\title{
Short promoters in viral vectors drive selective expression in mammalian inhibitory neurons, but do not restrict activity to specific inhibitory cell-types
}

\author{
Jason L. Nathanson ${ }^{1,2}$, Roberto Jappelli' , Eric D. Scheeff ${ }^{3}$, Gerard Manning ${ }^{3}$, Kunihiko Obata ${ }^{4}$, Sydney Brenner $^{1}$ \\ and Edward M. Callaway ${ }^{1 *}$
}

1 Systems Neurobiology Laboratories, Salk Institute for Biological Studies, La Jolla, CA, USA

2 Department of Bioengineering, University of California, San Diego, La Jolla, CA, USA

${ }^{3}$ Razavi Newman Center for Bioinformatics, Salk Institute for Biological Studies, La Jolla, CA, USA

${ }^{4}$ Neuronal Network Mechanisms Research Group, RIKEN Brain Science Institute, Saitama, Japan

\section{Edited by:}

Karl Deisseroth, Stanford University,

USA

\section{Reviewed by:}

Nathaniel Heintz,

The Rockefeller University, USA

Tom Clandinin,

Stanford University, USA

Alla Karpova, Howard Hughes Medical

Institute, USA

\section{${ }^{*}$ Correspondence:}

Edward M. Callaway, Salk Institute for Biological Studies, 10010 NTorrey Pines

Rd, La Jolla, CA 92037, USA.

e-mail: callaway@salk.edu
Short cell-type specific promoter sequences are important for targeted gene therapy and studies of brain circuitry. We report on the ability of short promoter sequences to drive fluorescent protein expression in specific types of mammalian cortical inhibitory neurons using adeno-associated virus (AAV) and lentivirus (LV) vectors. We tested many gene regulatory sequences derived from fugu (Takifugu rubripes), mouse, human, and synthetic composite regulatory elements. All fugu compact promoters expressed in mouse cortex, with only the somatostatin (SST) and the neuropeptideY (NPY) promoters largely restricting expression to GABAergic neurons. However these promoters did not control expression in inhibitory cells in a subtype specific manner. We also tested mammalian promoter sequences derived from genes putatively coexpressed or coregulated within three major inhibitory interneuron classes (PV, SST, VIP). In contrast to the fugu promoters, many of the mammalian sequences failed to express, and only the promoter from gene A930038C07Rik conferred restricted expression, although as in the case of the fugu sequences, this too was not inhibitory neuron subtype specific. Lastly and more promisingly, a synthetic sequence consisting of a composite regulatory element assembled with PAX6 E1.1 binding sites, NRSE and a minimal CMV promoter showed markedly restricted expression to a small subset of mostly inhibitory neurons, but whose commonalities are unknown.

Keywords: promoter, viral vector, fugu, transcription factor, cortex, inhibitory interneuron

\section{INTRODUCTION}

The mammalian cerebral cortex contains two major classes of neurons, excitatory and inhibitory. Distinguished from excitatory neurons by their primary neurotransmitter, $\gamma$-aminobutyric acid (GABA) rather than glutamate, inhibitory neurons make up a modest $10-20 \%$ of cortical neurons, yet play critical roles in modulating the activity of cortical circuits.

Cortical circuits consist of precise cell-type specific connections, whereby subcortical brain structures form connections with specific cortical inhibitory neuron subtypes (Freund and Gulyas, 1991; Hornung and Celio, 1992; Gibson et al., 1999). Inhibitory neurons also form selective inter-cortical connections to excitatory neurons and other inhibitory neurons (Somogyi, 1977; Meskenaite, 1997; Tamas et al., 1998; Defelipe et al., 1999; Gonchar and Burkhalter, 1999). Inhibitory neuron subtypes can be distinguished by morphology, intrinsic physiological properties and cellular function, and many can be uniquely differentiated by their gene expression profiles (Peters and Regidor, 1981; Kawaguchi, 1993; Kawaguchi and Kubota, 1996, 1997; Cauli et al., 1997; Gonchar and Burkhalter, 1997; Thomson and Deuchars, 1997; Parra et al., 1998; Gupta et al., 2000; Karube et al., 2004; Xu et al., 2006). Inhibitory neurons in rat can be divided into four largely non-overlapping groups, distinguished by the expression of either parvalbumin (PV), somatostatin (SST), cholecystokinin (CCK) or calretinin (CR) (Kawaguchi and Kubota, 1997). CCK and CR both overlap with vasointestinal polypeptide (VIP), but VIP does not overlap with PV or SST. Thus PV, SST, and VIP can also be used to define three largely non-overlapping cell groups. In mice, unlike rats, many CR expressing cells also express SST (Xu et al., 2006). Nevertheless, as in rats, three non-overlapping groups can be distinguished by PV, SST and VIP.

Recombinant adeno-associated virus and lentivirus are promising vectors for gene therapy because they can infect postmitotic neurons and mediate stable gene expression with minimal toxicity (Monahan and Samulski, 2000; Galimi and Verma, 2002). In addition, genetic methods for selective neuronal tracing or inactivation, for which viruses are the best delivery vehicles, have been developed to directly study particular cells, but the utility of these genetic tools requires the ability to selectively target gene expression to specific cell-types (Callaway, 2005; Luo et al., 2008). One such way is to use short cis-regulatory sequences (termed promoters), which can regulate gene expression using enhancers, silencers, and/or insulator/boundary elements. We used both rAAV2/1 (AAV2 backbone packaged with AAV1 capsid) (AAV) and VSV (vesicular stomatitis virus)-G-pseudotyped LV (LV) vectors for testing the activity and specificity of promoters. AAV can package DNA sequences up to $\sim 5$ kilobases $(\mathrm{kb}$ ) (Dong et al., 
1996) while LV can accommodate larger sequences up to $\sim 9 \mathrm{~kb}$ (Kumar et al., 2001). In the absence of helper virus or genotoxic stimuli, rAAV can either integrate randomly or form circular episomal provirus by intermolecular concatamerization (Duan et al., 1998; Yang et al., 1999). In contrast, LV mediates stable transduction by genome integration (Naldini et al., 1996a), creating the possibility that the same promoter and transgene will function differently in the two viruses. An additional difference between $A A V$ and $L V$ is viral tropism. We previously reported that rAAV2/1 transduces cortical inhibitory neurons more efficiently than excitatory neurons, while VSV-G-LV transduces excitatory neurons more efficiently than inhibitory neurons (Nathanson et al., 2009). Both AAV and LV also transduce glia. Therefore, AAV presumably provides a better system to test for differential expression amongst inhibitory neuron subtypes, while LV provides an alternative platform, and might be advantageous for determining whether a promoter drives expression in excitatory neurons. AAV and/or LV were used to test promoters derived from Takifugu rubripes (fugu), mouse, human and composite regulatory element sequences. We sought to create viruses with celltype specific promoters capable of driving expression in specific inhibitory neurons types, particularly the non-overlapping classes expressing either PV, SST or VIP.

With one-eighth the size of the human genome, an average gene density of one gene locus per $10.9 \mathrm{~kb}$ of genomic sequence and a similar repertoire of genes (Aparicio et al., 2002) the fugu genome provides an excellent collection of concise DNA regulatory regions. The intergenic regions, which are thought to contain the bulk of the gene regulatory information, are small and on the same scale as the capacities of AAV and LV. We hypothesized that for some fugu genes, the mere upstream intergenic region may contain genetic regulatory information nearly equivalent to that found in the much larger mammalian sequences, and could be used for controlling gene expression in the mammalian nervous system. Indeed, regulatory regions from the fugu isotocin and vasotocin genes drive specific expression in the corresponding oxytocin and vasotocin cells in the hypothalamus of transgenic rats and mice (Venkatesh et al., 1997; Gilligan et al., 2003). Also, a 6.5 -kb fragment of the fugu rhodopsin gene produced specific expression in the retina of transgenic mice (Zhang et al., 2003). Further analysis also revealed a 500-bp fragment capable of driving rod cell specific expression. Therefore, gene regulatory sequences specific for cell-types in the nervous system can be conserved across the large evolutionary distances between fugu and mammals.

The premise of our fugu hypothesis is that distinct subtypes of inhibitory neurons in the fugu telencephalon contain similar proteins and neuropeptides as in mammals, and that their expression may be similarly regulated. Telencephalic inhibitory neurons in mammals and teleosts, of which fugu is a member, and even the ancient sea lamprey, originate in the ganglionic eminences of the subpallial telencephalon (Melendez-Ferro et al., 2002). Therefore, even though fish lack a cortex, the telencephalic origin of the mammalian cortical inhibitory neurons is shared with fish. As evidence of this link, a reporter construct driven by the zebrafish distal-less homeobox enhancer DLX4/6, which is involved in the generation of inhibitory neurons in the ganglionic eminence, drove expression in cells that became mouse cortical inhibitory neurons (Stuhmer et al., 2002). Regulatory mechanisms responsible for the generation of inhibitory neurons are thus shared between fish and mammals. Importantly, the fish telencephalon expresses many of the same inhibitory genes for which we intend to test promoters - PV (Brinon et al., 1994), CR (Diaz-Regueira and Anadon, 2000; Castro et al., 2003), SST (Batten et al., 1990; Becerra et al., 1995) and NPY (Becerra et al., 1995; Castro et al., 1999).

We tested putative regulatory regions from fugu genes orthologous to mammalian inhibitory neuron specific markers PV, CR, SST and NPY. Additional candidate sequences for these cell-types were chosen from genes putatively coexpressed with these inhibitory cell-types in mouse. Sugino et al. (2006) used microarrays to profile gene expression in several inhibitory neuron subtypes. These coexpressed genes provided additional candidates for targeting inhibitory neuron subtypes. Motivated by this data, we chose the fugu genes titin-cap (TCAP) and secreted frizzled-related protein 2 (SFRP2), which respectively express in PV and SST cell-types in the mouse. In addition to the promoters targeting inhibitory neuron populations, we created a fugu promoter for $\alpha$-calcium/calmodulin-dependent protein kinase II (CAMK), a gene with expression restricted to excitatory neurons in the neocortex and hippocampus in rat (Liu and Jones, 1996) and monkey (Jones et al., 1994).

Since coexpressed genes may also be coregulated (Kielbase et al., 2004; Cora et al., 2005), Sugino et al.'s (2006) data provides a resource which we also used to apply bioinformatics analysis to suggest regulatory modules responsible for neuronal cell-type specific expression in mammals. First, we searched for transcription factor binding sites (TFBSs) conserved across coexpressed genes and across species. Distinctive TFBSs abundant in regulatory regions of genes coexpressed in a cell-type were hypothesized to be important for conferring cell-type specific expression. We chose human candidate genes containing regulatory sequences exhibiting a maximum number of TFBSs enriched in one cell-type, and a minimum number of TFBSs found in genes expressed by the other cell-types. Next, human promoter sequence segments were identified and cloned to putatively target SST, PV or VIP expressing inhibitory neuron subtypes.

Lastly, we tested promoters consisting of synthetic composite regulatory elements (CREs) consisting of TFBSs assembled with a minimal promoter. CREs consisting of more than one transcription factor binding site can drive highly specific patterns of gene regulation (Kel et al., 1995; Kel-Margoulis et al., 2002). These factor-factor interactions have been shown to be synergistic or antagonistic. Synergistic interactions can be a result of cooperative binding (Moreno et al., 1995; Brass et al., 1996; Butscher et al., 1998; Muhlethaler-Mottet et al., 1998; Okuno et al., 2001) or hierarchical loading (Linhoff et al., 1997). Antagonistic interactions can be a result of mutually exclusive binding because of competition for overlapping binding sites (Casolaro et al., 1995; Klein-Hessling et al., 1996; Takeuchi et al., 1998) or by repressor masking an activation domain (Diamond et al., 1990). We created CREs by combining DR1 (Okuno et al., 2001) or E1.1 (Scardigli et al., 2003) motifs with a neuron restrictive silencing element (NRSE) (Bessis et al., 1997; Millecamps et al., 1999) and a minimal cytomegalovirus (mCMV) promoter. 


\section{MATERIALS AND METHODS DESIGN OF FUGU REPORTER CONSTRUCTS}

Putative fugu gene orthologs were found by tblastn search and gene annotation of the following databases: Fugu rubripes v3.0 or v4.0 genome at JGI ${ }^{1}$, Queen Mary University of London ${ }^{2}$ and Ensembl ${ }^{3}$. In case of genes duplicated in the fish genome, a putative fugu orthologous gene was chosen based on preservation of order among short range neighboring genes and DNA sequence conservation. When this was compatible with the virus DNA capacity, the entire fugu upstream intergenic region was introduced into the viral expression vector. When the genomic sequence exceeded the capacity of the viral expression vector, the maximal upstream sequence proximal to the gene $5^{\prime}$ end was chosen. Sequences were isolated from the fugu genomic DNA by PCR amplification using primers flanked with restriction enzyme cloning sites.

Sequences for the fugu viral vectors were as follows.

1. fCAMK (AAV) - $\alpha$-calcium/calmodulin-dependent protein kinase II, 2567-bp, Fugu 2002 assembly: chrUn:257,733,699257,736,265 (UCSC), upstream of Ensembl transcript SINFRUT00000157719 (CAMK). Fugu 2004 assembly: chrUn:114,469,050-114,471,616 (UCSC), upstream of Ensembl transcript ENSTRUT00000018600 (CAMK).

2. fCR (AAV) - calretinin, 2595-bp, Fugu 2002 assembly: chrUn:239,797,309-239,799,903 (UCSC), upstream of Ensembl transcript SINFRUT00000150025. Fugu 2004 assembly: chrUn:47,433,038-47,435,619 (UCSC), upstream of Ensembl transcript ENSTRUT00000046308 (CR).

3. fCR (LV) - 6326-bp, A similar, but larger region of fCR (AAV). Fugu 2002 assembly: mapped to chrUn:239,793,595239,799,905 (UCSC). Fugu 2004 assembly: mapped to chrUn:47,429,323-47,435,621 (UCSC).

4. fNPY (AAV) - neuropeptide Y, 2605-bp, Fugu 2002 assembly: chrUn:103,680,529-103,683,131 (UCSC), upstream of Ensembl transcript SINFRUT00000153449 (NPY). Fugu2004 assembly: chrUn:287,512,332-287,514,956 (UCSC), upstream of Ensembl transcript ENSTRUT00000016839 (NPY).

5. ANPY (LV) - 6443-bp A similar, but larger region of ANPY (AAV). Fugu 2002 assembly: mapped to chrUn:103,680,529103,686,955 (UCSC). Fugu 2004 assembly: mapped to chrUn:287,509,165-287,514,956 (UCSC).

6. fPV (AAV) - parvalbumin, 2395-bp, Fugu 2002 assembly: chrUn:103,113,651-103,116,040 (UCSC), upstream of Ensembl transcript SINFRUT00000151321 (PV). Fugu 2004 assembly: chrUn:316,053,780-316,056,172, but is no longer identified as the fugu ortholog. The new fugu ortholog is Ensembl transcript ENSTRUT00000000079.

7. $\mathrm{fPV}(\mathrm{LV})$ - 2893-bp A similar, but larger region of $\mathrm{fPV}$ (AAV). Fugu 2002 assembly: mapped to chrUn:103,113,151103,116,041 (UCSC). Fugu 2004 assembly: mapped to chrUn:316,053,280-316,056,173 (UCSC).

${ }^{1}$ http://genome.jgi-psf.org

${ }^{2}$ http://fugu.biology.qmul.ac.uk

${ }^{3}$ http://www.ensembl.org
8. fSFRP2 (AAV) - secreted frizzled-related protein 2, 1218-bp, Fugu 2002 assembly: chrUn:13,504,648-13,505,865 (UCSC), upstream of Ensembl transcript SINFRUT00000138275 (SFRP2). Fugu 2004 assembly: chrUn:96,858,434-96,859,651 (UCSC), part of first intron of Ensembl transcript ENSTRUT00000017303 (SFRP2).

9. fSST (AAV) - somatostatin, 2597-bp, Fugu Assembly 2002: chrUn:228,946,036-228,948,614(UCSC), upstreamofEnsembl transcript SINFRUT00000151429 (SST). Fugu Assembly 2004: chrUn:232,110,513-232,113,091 (UCSC), downstream region of Ensembl transcript ENSTRUT00000025350 (SST).

10. fSST (LV) - 4406-bp A similar, but larger region of fSST (AAV). Fugu 2002 assembly: mapped to chrUn:228,946,036228,950,367 (UCSC). Fugu 2004 assembly: mapped to chrUn:232,108,687-232,113,091 (UCSC).

11. fTCAP (AAV) - titin cap, 2656-bp, Fugu 2002 assembly: chrUn:17,827,063-17,829,718 (UCSC), upstream of Ensembl transcript SINFRUT00000161814. Fugu 2004 assembly: chrUn:49,879,491-49,882,146 (UCSC), upstream of Ensembl transcript ENSTRUT00000041782 (TCAP).

\section{DESIGN OF MAMMALIAN REPORTER CONSTRUCTS}

Cortical gene expression data (Sugino et al., 2006) were analyzed for the excitatory CT6 and YFPH cell-types and for the three inhibitory G30, GIN, and G42 cell-types. Genes with more than a 3-fold enrichment compared to any other cell-type were considered candidate coexpressed genes. The inhibitory cell-types were generally classified by the designation of one of their member genes: G30VIP, G42-PV (note: PV not actually restricted to only this group, since it was also expressed in the excitatory neuron population YFPH), GIN-SST.

We analyzed the promoters of human genes specific to these cell-types to see if we could find a sequence segment that would give cell-type specific expression. To this end, we considered upstream segments of the candidate coexpressed genes, including multiple sequences for each gene if multiple alternate start sites existed. Some of the genes from the microarray analysis did not appear to be cell-type specific by in situ hybridization according to the Allen Mouse Brain Atlas (Lein et al., 2007). Genes that were not likely restricted to inhibitory neurons were discarded, leaving 25 genes for G30-VIP, 16 genes for G42-PV and 12 genes for GIN-SST (see Table $\mathbf{S 1}$ in Supplementary Material).

In order to enhance the probability of isolating a $3-\mathrm{kb}$ segment from these promoters that would provide cell-type specific expression, we subjected the sequences to computational analysis. We applied a phylogenetic footprinting approach (Zhang and Gerstein, 2003), coupled with TRANSFAC matrices (Matys et al., 2003) to predict putative TFBS. Each human promoter sequence was used to gather orthologous upstream regions from 16 vertebrate species using the UCSC Genome Browser Database (Kent et al., 2002; Karolchik et al., 2008), and a multi-species promoter alignment was assembled with DIALIGN (Morgenstern, 1999). Each sequence was then searched against all vertebrate TRANSFAC matrices using MATCH (Kel et al., 2003) with the "minSUM" score cutoff, which seeks to minimize the sum of both false positive and false negative matches. Putative TFBS were then mapped back to the alignment and used to determine conservation levels 
for the putative TFBS seen in human (these were considered "conserved" if they were also present in $>35 \%$ of non-primate mammals in the alignment at the identical location). Presence/absence of conserved putative human TFBS were then collected for each promoter and compared between cell types. To avoid biasing TFBS representation for genes with multiple alternative start sites, this initial analysis was done by combining all of the alternative start site sequences for each gene (i.e. each gene promoter was only counted once).

We sought to identify TFBSs characteristic of each group of genes distinctive to each cell-type, and to find the promoters that had a maximum number of sites for this cell-type and a minimum number of sites for TFBSs characteristic of other celltypes. The analysis did not identify any TFBS enriched in most promoters of one gene group and completely absent in promoters of other groups. However, we did find sites that were clearly overrepresented in each of the three groups of coexpressed genes (see Tables S2-4 in Supplementary Material). Distinctive TFBS for each cell type were defined as those conserved in at least $10 \%$ of promoters from that cell type, and enriched relative to the other two cell types by a ratio of $>1.5$ (or enriched relative to one cell type by a ratio of $>2$ and the other by a ratio of $>1.2$, to allow for sites that were particularly distinctive for only one of the other cell types). We next determined which genes had promoters which maximized TFBSs distinctive for one cell-type and minimized TFBSs distinctive for other cell-types. We also selected the optimal alternative start site promoter in genes which had multiple start sites. In almost all cases, the optimal promoter fragment was the one that appeared to be immediately proximal to the coding region of the primary isoform of the gene.

Sequences for the mammalian viral vectors were as follows. Sequences 6-12 were chosen based on the computational analysis described above. Sequences 1-5 were chosen based on previous publications or other bioinformatic analyses.

1. hSyn (AAV) - synapsin I, 468-bp, Human 2006 assembly: chrX:47,364,154-47,364,622 (UCSC) (Kugler et al., 2003).

2. mGAD2 (LV) - glutamate decarboxylase 2, 4415-bp, Mouse 2007 assembly: chr2:22,473,768-22,478,182 (UCSC).

3. mA93 (AAV) - riken gene A930038C07Rik, 2694-bp. Consists of two conserved regions, which we concatenated. Mouse 2007 assembly: chr6:65,592,490-65,594,288 and chr6:65,620,737-65,621,604 (UCSC).

4. mSST (LV) - somatostatin, 6001-bp, Mouse 2007 assembly: chr16:23,890,831-23,896,831 (UCSC).

5. hPDGFRA (AAV) - platelet derived growth factor receptor alpha, 2650-bp, Human 2006 assembly: chr4:54,787,69154,790,341 (UCSC).

6. hGRM1 (AAV) - glutamate receptor, metabotropic 1, 2585bp, Human 2006 assembly: chr6:146,389,761-146,392,345 (UCSC).

7. hNPPC (AAV) - c-type natriuretic peptide precursor, 2585bp, Human 2006 assembly: chr2:232,499,151-232,501,735 (UCSC).

8. hADM (AAV) - adrenomedullin, 2555-bp, Human 2006 assembly: chr11:10,281,564-10,284,118 (UCSC).
9. hST3GAL6 (AAV) - type 2 lactosamine alpha-2,3-sialyltransferase, 2739-bp, Human 2006 assembly: chr3:99,931,56299,934,300 (UCSC).

10. hRREB1 (AAV) - ras responsive element binding protein 1, 2715-bp, Human 2006 assembly: chr6:7,050,563-7,053,277 (UCSC).

11. hDIO2 (AAV) - deiodinase, iodothyronine, type II, 2568bp, Human 2006 assembly: chr14:79,747,568-79,750,140 (UCSC).

12. hNR2F2 (AAV) - nuclear receptor subfamily 2, group F, member 2, 2568-bp, Human 2006 assembly: chr15:94,667,97694,670,543 (UCSC).

\section{DESIGN OF COMPOSITE REGULATORY ELEMENT (CRE) REPORTER CONSTRUCTS}

Three CREs were constructed. Elements were ordered as oligonucleotides, and assembled as a DNA cassette.

1. E1.1-mCMV (AAV) - four E.1.1 binding sites (5'TCATTCAC GCCTAGAAGCAG3'), as described in Scardigli et al. (2003), were assembled upstream of a minimal CMV promoter consisting of 58 base pairs near the $3^{\prime}$ end of the CMV promoter. The distance between the $3^{\prime}$ most E1.1 site TAGGCGTGTAC GGTGGGAGGTCTATATAAGCAGAGCTGGTTTAGTGAAC CGTCAGATC and the mCMV was $59 \mathrm{bp}$. This cassette was cloned into the AAV transfer vector. (AAV-E1.1)

2. E1.1-NRSE-mCMV (AAV) - the E1.1-mCMV construct plus a neuron restrictive silencing element (NRSE) binding site (5'TTCAGCACCACGGACAGCGCC3') inserted between the E1.1 sites and the mCMV. The distance between the $3^{\prime}$ most E1.1 site and NRSE was $61 \mathrm{bp}$, and between NRSE and mCMV was $3 \mathrm{bp}$. This construct was cloned into the AAV transfer vector. (AAV-E1.1-NRSE)

3. NRSE-DR1-mCMV (AAV) - a single DR1 binding site $\left(5^{\prime} \mathrm{T}\right.$ CTAGGGGTCAAAGGTCACCGG3'), as described in Okuno et al. (2001), was inserted between an upstream NRSE binding site (5'TTCAGCACCACGGACAGCGCC3') and downstream of a minimal CMV promoter. The distance between NRSE and DR1 was $9 \mathrm{bp}$, and between DR1 and mCMV was $12 \mathrm{bp}$. This construct was cloned into the AAV transfer vector. (AAV-DR1-NRSE)

\section{VIRUS PRODUCTION}

Promoters were cloned into either ITR flanked AAV transfer vectors (Kaspar et al., 2002) or LV transfer vectors (pCSC-SP-PW, Marr et al., 2004) expressing green fluorescent protein (GFP) or red fluorescent protein DsRed-Express (RFP). Plasmids were purified using endotoxin-free maxiprep kits (Qiagen, Valencia, CA, USA). Recombinant rAAV2/1 (AAV2 backbone packaged with AAV1 capsid) was produced by $\mathrm{BBS} / \mathrm{CaCl} 2$ or PEI mediated co-transfection of 293 T cells with the AAV2 ITR flanked transfer vector, pXR1 (AAV type-1) and pXX6-80 (Ad5 genome) (Rabinowitz et al., 2002). Cells were harvested and lysed, treated with benzonase (Sigma-Aldrich D9542, St. Louis, MO, USA), and virus was concentrated and purified by iodixanol gradient centrifugation (Zolotukhin et al., 1999). Lentivirus was produced by $\mathrm{HBS} / \mathrm{CaCl} 2$ mediated co-transfection of $293 \mathrm{~T}$ cells with the LV transfer vector and plasmids 
pMDL, pRev, and pVSVG (Naldini et al., 1996b). Media was collected and virus concentrated through multiple centrifugation steps (Tiscornia et al., 2006).

\section{VIRUS TITRATION}

Viral genomes were quantified using SYBR Green with a qPCR cycler (ABI 7900HT, Applied Biosystems, Foster City, CA, USA). AAV genomic DNA was isolated by lysing AAV in $2 \mathrm{M} \mathrm{NaOH}$ for $30 \mathrm{~min}$ at $56^{\circ} \mathrm{C}$, and neutralizing with $\mathrm{HCl}$. LV was incubated with DNase I (NEB, Ipswich, MA, USA), and RNA isolated (QIAamp MinElute Virus Spin kit, Qiagen, Valencia, CA, USA), followed by reverse transcription (Superscript III kit, Invitrogen, Carlsbad, CA, USA). Viral DNA was diluted and compared to a standard curve created from a known quantity of transfer vector. Infectious titers were determined by infecting confluent 293T cells with serial dilutions of virus, followed $60 \mathrm{~h}$ later by two PBS washes, trypsinization, centrifugation to isolate cells, DNA isolation by proteinase $\mathrm{K}$ digestion in SNET lysis buffer $(20 \mathrm{mM}$ Tris (pH 8), $1 \mathrm{mM} \mathrm{EDTA,} 1 \%$ SDS, $0.4 \mathrm{M} \mathrm{NaCl}$ ) at $55^{\circ} \mathrm{C}$ for $12 \mathrm{~h}$, followed by alcohol precipitation. Concentration of the precipitated DNA, composed of cellular and viral DNA, was determined by spectrophotometry. qPCR was performed in the same manner as used to determine the genomic titer. The titer was normalized by the concentration of precipitated DNA loaded into the PCR reaction.

\section{STEREOTAXIC VIRUS INJECTIONS}

Adult wild-type ICR mice, wild-type C57BL/6J mice, GAD67-GFP ( $\Delta$ neo) knock-in mice (Tamamaki et al., 2003), adult wild-type Sprague-Dawley rats, and a $\sim 4$-year old adult monkey (Macaca mulatta) were injected with viruses following procedures approved by the Salk Institute Animal Care and Use Committee guidelines. Animals were anesthetized using a cocktail of ketamine and xylazine, and/or isoflurane. Virus was delivered via a glass micropipette $(\sim 30-50 \mu \mathrm{m}$ tip diameter) using air pressure applied via a Picospritzer II (General Valve Corporation, Fairfield, NJ, USA). Stereotaxic injections to mouse somatosensory cortex: $3.0 \mathrm{~mm}$ lateral, $-0.5 \mathrm{~mm}$ to $-1.0 \mathrm{~mm}$ bregma, at depths of 0.75 and $0.45 \mathrm{~mm}$; DG: $1.25 \mathrm{~mm}$ lateral, $-2.0 \mathrm{~mm}$ bregma, at depths of $1.75,1.45$ and $1.10 \mathrm{~mm}$; thalamus: $1.25 \mathrm{~mm}$ lateral, $-2.0 \mathrm{~mm}$ bregma, at depths 2.25 and $2.0 \mathrm{~mm}$. Stereotaxic injection to rat somatosensory cortex: $5.0 \mathrm{~mm}$ lateral, $-2.3 \mathrm{~mm}$ bregma, at depths of $2.0,1.3$ and $0.6 \mathrm{~mm}$. Stereotaxic injections to monkey precentral gyrus (motor cortex) and postcentral gyrus (somatosensory cortex) at depths of 1.2, 0.8 and $0.4 \mathrm{~mm}$. Five-minute injections at each depth usually corresponded to $1-2 \mu \mathrm{l}$ of virus, delivered at $20 \mathrm{psi}$, with 1 pulse per second. The pulse duration was adjusted to modulate the flow rate.

\section{HISTOLOGY AND IMMUNOHISTOCHEMISTRY}

25-40 $\mu \mathrm{m}$ thick sections cut on a freezing microtome were stained with one or more of the following antibodies: Chicken anti-GFP (Aves Labs GFP-1020 1:500, Tigard, OR, USA), Rabbit (Rb) anti-DsRed (Clontech 632496 1:200, Mountain View, CA, USA), Mouse (Ms) anti-NeuN (Millipore MAB377 1:100, Billerica, MA, USA), Rb anti-PV28 (Swant), Ms anti-PV (Sigma P3088), Rb
anti-PV28 (Swant 1:1000), Ms anti-PV (Sigma P3088 1:1000), Rb anti-CR (Swant 1:1000), Rb anti-VIP (ImmunoStar 20077 1:500), $\mathrm{Rb}$ anti-NPY(Chemicon AB1915 1:500), Rat anti-Somatostatin (Chemicon MAB354 1:200), and Ms anti-CAMKii (Chemicon MAB869 1:500). As secondary antibodies we used one or more of Cy2 (Jackson Immuno 1:100, West Grove, PA, USA), AlexaFluor 568 (Invitrogen A11036 1:100, Carlsbad, CA, USA), RhodX (Jackson Immuno 1:100), and Cy5 (Jackson Immuno 1:100) fluorophores raised against the appropriate species. Mounted sections were counterstained with $10 \mu \mathrm{M}$ DAPI (Sigma-Aldrich D9542, St. Louis, MO, USA) in PBS. Sections were dehydrated through xylenes and coverslipped using Krystalon (EMD Chemicals, Gibbstown, NJ, USA).

\section{IMAGING AND CELL-COUNTING}

Quantitative data described in the results are based on observations of label from at least 2, but typically 5 sections, from 3 or more animals (except for AAV-fPV and results from monkey which are from a single animal). Except for the AAV-fSST-RFP in GAD67-GFP analysis, cells in all cortical layers in each section were combined, as the inhibitory neuron subtype variability across layers was presumed to be less than the variability between sections. For each injection analyzed, tissue sections were scanned to identify the region with the highest density of labeling and this was considered the center of the injection site. Neurons expressing reporter from the injected vector were counted in this section and up to eight adjacent sections and scored for no overlap or double-label with markers identifying neuron subtypes. The total numbers of labeled cells counted and scored varied between sections and layers due to differences in labeling density for different vectors and cell-type antibodies. Typically, $\sim 10$ double-labeled cells were counted per section [range: 0-163 (AAV-fNPY tissue stained with anti-PV antibody)] for cell-type specific antibody labeling, and a total of more than 170 cells for each vector. For AAV-fSST-RFP in GAD67-GFP mice, 8 sections with 17-38 cells per section were counted.

To count and score labeled cells, fluorophores were imaged independently at three confocal planes at $10 \times$ or $20 \times$ magnification using either a Nikon TE300 with a Bio-Rad radiance 2100 system or an Olympus BX51 with a Bio-Rad Radiance 2100MP system. Images were projected and merged in RGB space. Quantification of overlap of cell labeling was done using the confocal images in Adobe Photoshop. Cortical layers were determined by DAPI staining.

\section{RESULTS}

To target specific neuron cell-types in mammals, we tested regulatory sequences derived from multiple sources: (i) promoter sequences derived from putative orthologous fugu genes, (ii) mammalian promoter segments from genes putatively co-expressed in known inhibitory neuron subtypes, and (iii) assembled composite regulatory elements (CREs) containing TFBSs.

We used both AAV and LV as delivery vectors. Most of the viruses were tested for specificity in mouse somatosensory cortex. Some of the viruses were also tested in mouse dentate gyrus or thalamus, or in the cortex of rat or monkey. Cell-type specificity was determined by cellular morphology and co-localization with 
inhibitory neuron subtype specific antibodies parvalbumin (PV), calretinin (CR), somatostatin (SST), neuropeptide Y (NPY) and/or vasoactive intestinal polypeptide (VIP).

\section{FUGU PROMOTERS}

\section{Fugu promoters in AAV drove expression in mouse cortex}

Fugu $5^{\prime}$ intergenic DNA sequences up to $2.8 \mathrm{~kb}$, including $5^{\prime}$ UTRs, were cloned into green fluorescent protein (GFP) or red fluorescent protein DsRed-Express (RFP) reporter vectors (Figure 1). All but one of the vectors tested aimed to target inhibitory neurons. The exception was the fugu $\alpha$-calcium/calmodulin-dependent protein kinase II (AAV-fCAMK) vector targeting excitatory neurons. All fugu promoters tested drove expression in mouse somatosensory cortex (Figures 2 and 3, Table 1), but the expression strength varied between vectors. AAV expression of fugu somatostatin (AAV-fSST) and fugu neuropeptide Y (AAV-fNPY) vectors were widespread in all cortical layers with transduction often observed more than $300 \mu \mathrm{m}$ from the injection column (Figures 2A,D). Calretinin (AAV-fCR), parvalbumin (AAV-fPV), secreted frizzed-related protein 2 (AAV-fSFRP2), titin-cap (AAV-fTCAP) and AAV-fCAMK vectors showed expression usually confined to less than $200 \mu \mathrm{m}$ from the injection site (Figures 2G,J and 3A,D,G). Depending on the virus injection, most vectors showed more widespread expression in layers $2 / 3$ and $5(\sim 500 \mu \mathrm{m}$ laterally). Many neuron types in layers $2 / 3$ and 5 send projections to the brain surface, and thus cells far from the injection site are capable of taking up virus which often spreads laterally beneath the pia following pressure injections.

Examination of the morphologies of cells labeled with AAVfSST, AAV-fNPY, AAV-fPV and AAV-fCAMK indicated expression was almost entirely restricted to neurons, with no visible glial cell expression (Figures 2A-I and 3G-I). AAV-fCR, AAV-fSFRP 2 and AAV-fTCAP expression was also mostly neuronal, but the presence of small, compact transgene labeled cells with bushy processes indicated that promoters were also active in glia (Figures $2 \mathbf{J}-\mathbf{L}$ and 3A-F, glia marked with upward arrows). Pyramidal shaped cell bodies and apical dendrites are characteristic traits of cortical pyramidal neurons (excitatory neurons). Due to the preservation of apical dendrites, pyramidal neuron identification was best in brain sections cut closest to the coronal plane, parallel to the apical dendrites. Non-ideal cuts do not show continuous apical dendrite label. As predicted, AAV-fCAMK showed many pyramidal cell bodies and apical dendrites (Figures 3G-I, pyramidal neurons marked with downward arrows). However, injections of AAV-fPV and AAV-fTCAP also labeled excitatory neurons (Figures 2G-I and 3D-F). The labeled pyramidal cells were typically located in layer 5. In contrast, AAV-fSST, AAV-fNPY, AAV-fCR and AAVfSFRP2 did not show many cells morphologically identifiable as excitatory (Figures 2A-F,J-L and 3A-C). All promoters, including fCAMK (Figures 3G-I), showed scattered non-pyramidal cells in all cortical layers consistent with expression in inhibitory neurons.

Taken together these results indicate that only AAV-fSST and AAV-fNPY restrict expression to mouse inhibitory interneurons. The degree to which promoter specificities and viral tropism contribute to selective inhibitory neuron expression will be considered in the context of further results presented below.

\section{Fugu promoters in AAV drove expression in rat and monkey cortex}

Injections of AAV-fSST, AAV-fNPY and AAV-fCAMK into rat and monkey somatosensory cortex showed robust transgene expression that was almost entirely restricted to neurons (Figure 4). As in the mouse cortex, morphology of AAV-fSST expressing cells suggested that nearly all of the labeled cells were inhibitory neurons (Figures 4A-C). In contrast, the morphology of AAV-fNPY and AAV-fCAMK expressing cells in rat and monkey cortex indicated expression in both pyramidal and inhibitory cells (Figures 4D-I). As predicted, AAV-fCAMK labeled many pyramidal neurons. In comparison, AAV-fNPY drove expression in only a few pyramidal neurons. Staining AAV-fCAMK sections with CAMK antibody
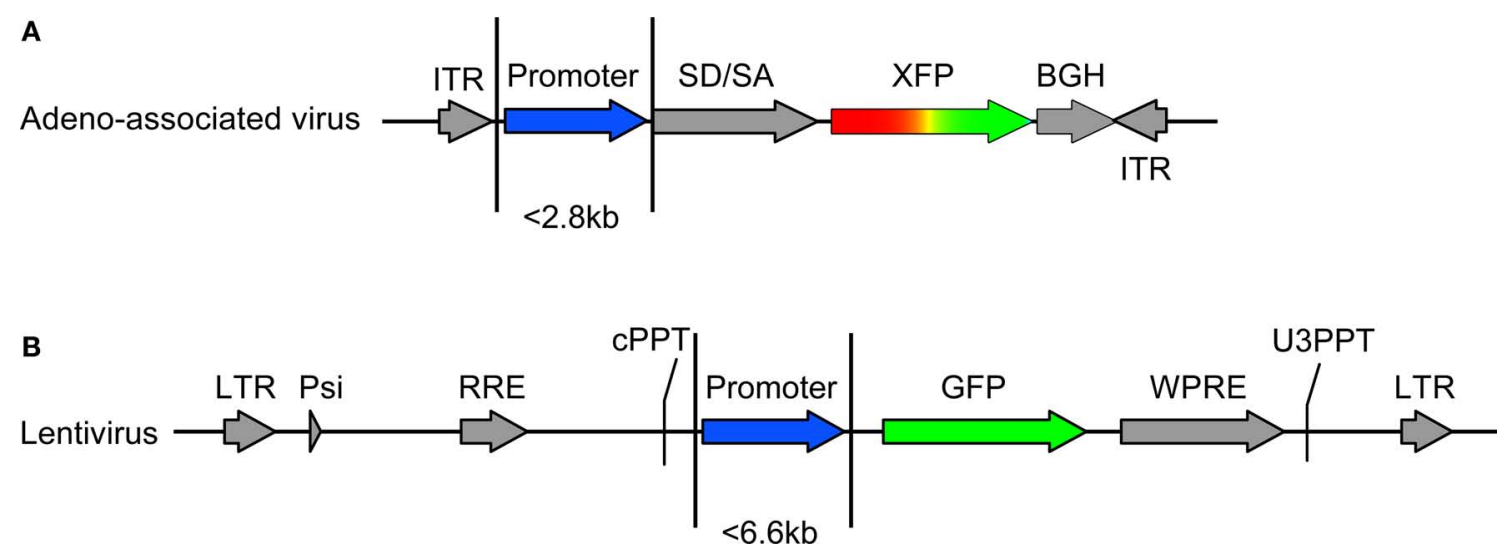

FIGURE 1 | Vector design. Transfer vectors for adeno-associated virus (AAV) and lentivirus (LV) were constructed as in (A) and (B), respectively. The capacity of AAV and LV allowed promoter sequences of approximately 2.8 and $6.6 \mathrm{~kb}$, respectively. AAV contained either the green fluorescent protein (GFP) or red fluorescent protein DsRed-Express (RFP). Lentivirus contained GFP. Components of AAV include: ITR - AAV2 inverted terminal repeat, SD/SA - splice donor splice acceptor intronic element (human beta globin), XFP -either GFP or RFP, BGH - poly(A). Components of LV include: LTR - long terminal repeat, Psi - element for viral genome packaging, RRE - Rev response element, cPPT - central polypurine tract, WPRE - woodchuck hepatitis virus posttranscriptional regulatory element, U3PPT - upstream border of the $3^{\prime}$ long terminal repeat polypurine tract. Viruses were made as described in Tables 1-3. 

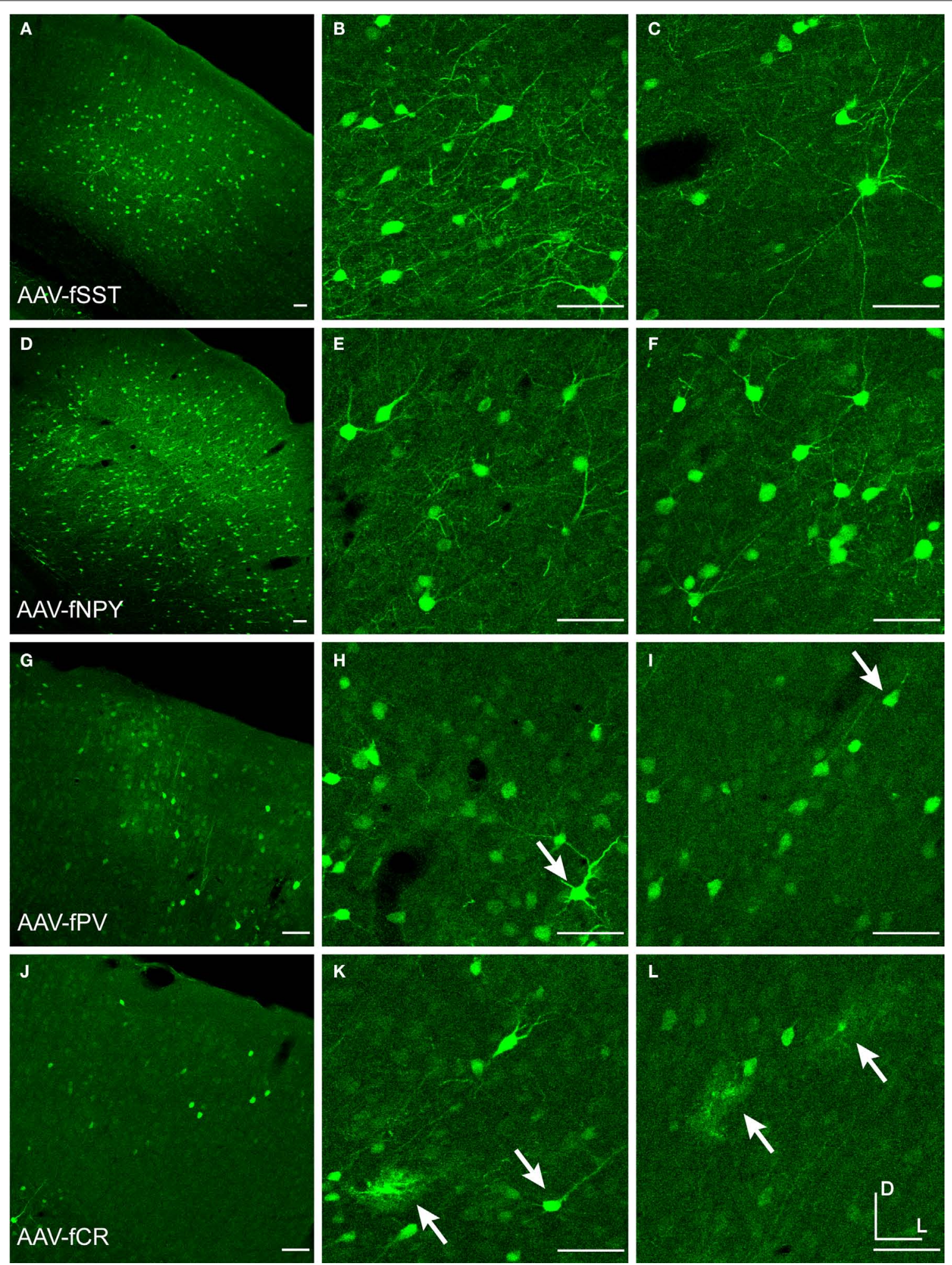

FIGURE 2 | Fugu promoters in AAV expressed in mouse cortex. Fugu promoters in AAV injected in mouse somatosensory cortex expressed GFP. Wide-angle images in the left column $(\mathbf{A}, \mathbf{D}, \mathbf{G}, \mathbf{J})$ show multilayer viral expression patterns. Close-up images centered on layer 5 and layer 2/3 are shown in the middle column (B,E,H, $\mathbf{K})$ and right column $(\mathbf{C}, \mathbf{F}, \mathbf{I}, \mathbf{L})$, respectively. Expression of fugu promoters in AAV are shown in rows: somatostatin [AAV-fSST, (A-C)], neuropeptide Y [AAV-fNPY, (D-F)], parvalbumin [AAV-fPV, (G-I)], and calretinin [AAV-fCR, (J-L)]. Upward arrows mark glia and downward arrows mark excitatory pyramidal neurons. Dorsal (D) and lateral (L) directions for all images are as indicated in (L). Scale bars are $50 \mu \mathrm{m}$. 

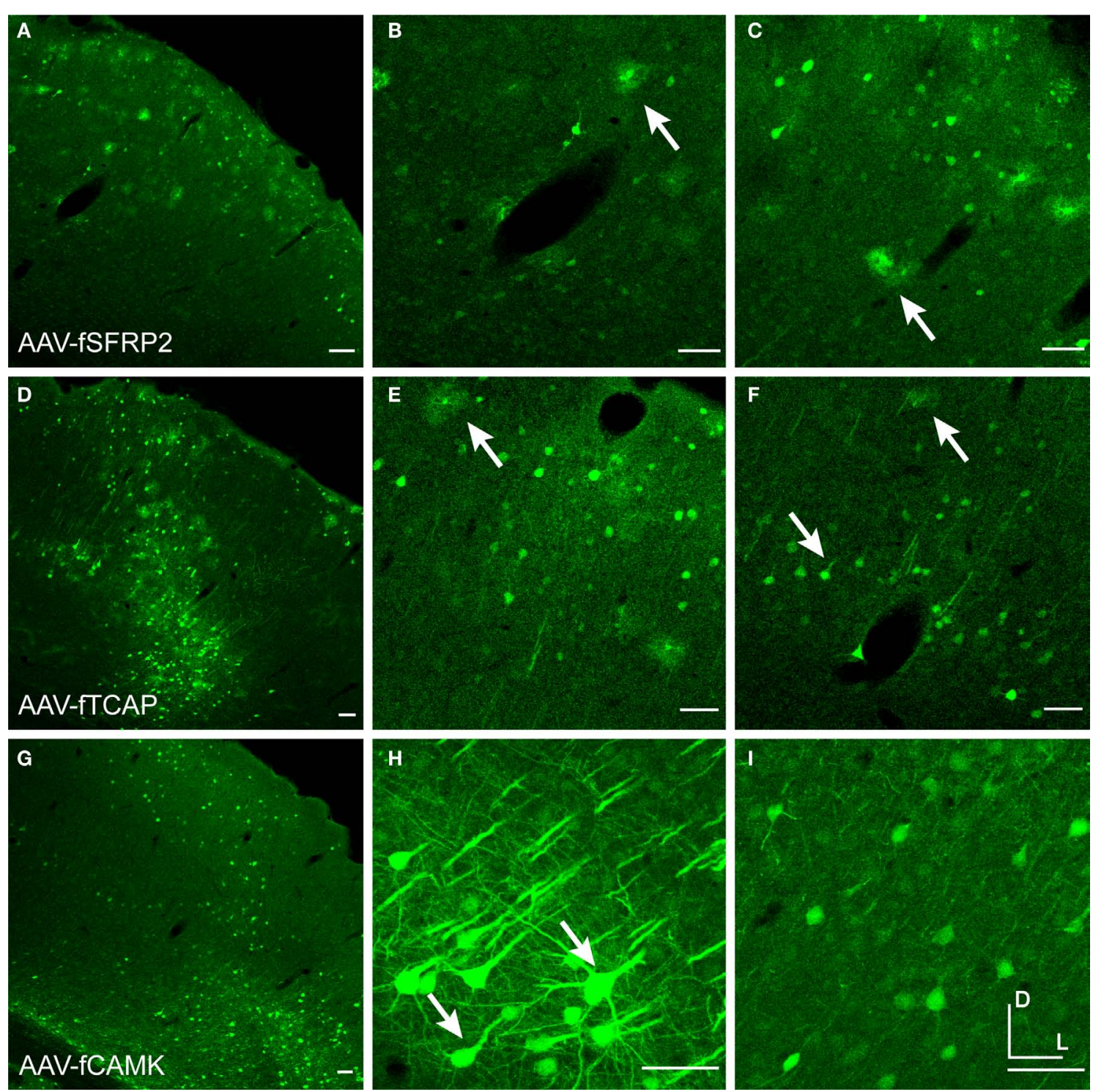

FIGURE 3 | Fugu promoters in AAV expressed in mouse cortex. Fugu promoters in AAV injected in mouse somatosensory cortex expressed GFP. Wide-angle images in the left column $(\mathbf{A}, \mathbf{D}, \mathbf{G})$ show multilayer viral expression patterns. Close-up images centered on layer 5 and layer $2 / 3$ are shown in the middle column $(\mathbf{B}, \mathbf{E}, \mathbf{H})$ and right column $\mathbf{( C , F , I ) , ~ r e s p e c t i v e l y . ~ E x p r e s s i o n ~ o f ~ f u g u ~}$ promoters in AAV are shown in rows: secreted frizzled-related protein 2 [AAV-fSFRP2, (A-C)], titin-cap [AAV-fTCAP, (D-F)] and $\alpha$-calcium/calmodulindependent protein kinase II [AAV-fCAMK, (G-I)]. Upward arrows mark glia and downward arrows mark excitatory pyramidal neurons. Dorsal (D) and lateral (L) directions for all images are as indicated in (I). Scale bars are $50 \mu \mathrm{m}$. confirmed some of the AAV-fCAMK labeled cells were excitatory. However, staining of each of these viruses with inhibitory neuron antibody markers NPY, CR and SST confirmed that at least some of the labeled cells from each virus, including AAV-fCAMK, were inhibitory. Therefore, while AAV-fCAMK drove expression in large numbers of excitatory neurons, this vector does not restrict expression to excitatory neurons, and may not be as selective as the mouse CAMK promoter version previously characterized in a lentiviral expression vector (Dittgen et al., 2004; Nathanson et al., 2009). Together with the mouse results, we observed that in rodents, of all the fugu promoters tested, only AAV-fSST restricted expression to inhibitory neurons.

\section{Fugu promoters in AAV drove expression in dentate gyrus (DG) and thalamus}

We tested the fugu promoters in dentate gyrus of the hippocampus, which also contains diverse populations of neurons. The granule cell layer (GZ) of the DG is composed predominantly of excitatory granule cells, while inhibitory neurons are concentrated along the inner subgranular lining of the GZ (SGZ) (Patton and McNaughton, 1995). In the PoDG, about half of the neurons are inhibitory and half of the neurons are excitatory mossy cells (Blasco-Ibanez and Freund, 1997), yet some of the mossy cells in the PoDG express CR, but are not inhibitory (Blasco-Ibanez and Freund, 1997). AAV-fSST almost exclusively labeled cells in 
Table 1 | AAV and LV vectors with fugu promoters.

\begin{tabular}{|c|c|c|c|c|c|c|c|c|}
\hline Gene/promoter & Symbol(a) & Transgene & $\begin{array}{l}\text { Genomic titer } \\
\text { (genomes/ml) }\end{array}$ & $\begin{array}{l}\text { Promoter } \\
\text { length }^{(\mathbf{b})}\end{array}$ & Target cell-type & $\begin{array}{l}\text { Glia } \\
\text { expression }^{(c)}\end{array}$ & $\begin{array}{l}\text { Excitatory } \\
\text { neuron } \\
\text { expression }^{(\mathrm{c})}\end{array}$ & $\begin{array}{l}\text { Inhibitory } \\
\text { neuron } \\
\text { expression (c) }\end{array}$ \\
\hline Calretinin & $A A V-f C R$ & GFP & $9.70 E+10$ & 2595 & $\begin{array}{l}\text { Inhibitory neuron } \\
\text { subtype (CR) }\end{array}$ & + & - & + \\
\hline NeuropeptideY & AAV-fNPY & GFP & $6.70 E+10$ & 2605 & $\begin{array}{l}\text { Inhibitory neuron } \\
\text { subtype (NPY) }\end{array}$ & - & - & $+1+$ \\
\hline \multirow[t]{2}{*}{ Somatostatin } & AAV-fSST & GFP & $1.40 \mathrm{E}+11$ & 2597 & $\begin{array}{l}\text { Inhibitory neuron } \\
\text { subtype (SST) }\end{array}$ & - & - & H+ \\
\hline & & RFP & $5.92 E+11$ & & & - & + & $+H$ \\
\hline Parvalbumin & AAV-fPV & GFP & $1.20 E+11$ & 2395 & $\begin{array}{l}\text { Inhibitory neuron } \\
\text { subtype (PV) }\end{array}$ & - & + & + \\
\hline $\begin{array}{l}\text { Secreted Frizzled } \\
\text { Receptor Protein } 2\end{array}$ & AAV-fSFRP2 & GFP & $2.70 E+11$ & 1218 & $\begin{array}{l}\text { Inhibitory neuron } \\
\text { subtype (SST) }\end{array}$ & + & - & + \\
\hline Titin Cap & AAV-fTCAP & GFP & $2.00 E+11$ & 2656 & $\begin{array}{l}\text { Inhibitory neuron } \\
\text { subtype (PV) }\end{array}$ & + & + & + \\
\hline $\begin{array}{l}\alpha \text {-calcium/ } \\
\text { calmodulin- } \\
\text { dependent protein } \\
\text { kinase II }\end{array}$ & AAV-fCAMK & GFP & $4.5 E+10$ & 2567 & Excitatory neurons & - & + & ++ \\
\hline Calretinin & LV-fCR & GFP & $2.01 E+10$ & 6326 & $\begin{array}{l}\text { Inhibitory neuron } \\
\text { subtype (CR) }\end{array}$ & - & + & + \\
\hline NeuropeptideY & LV-fNPY & GFP & $4.51 E+10$ & 6443 & $\begin{array}{l}\text { Inhibitory neuron } \\
\text { subtype (NPY) }\end{array}$ & - & + & + \\
\hline Somatostatin & LV-fSST & GFP & & 4406 & $\begin{array}{l}\text { Inhibitory neuron } \\
\text { subtype (SST) }\end{array}$ & - & + & + \\
\hline Parvalbumin & LV-fPV & GFP & $3.54 \mathrm{E}+10$ & 2893 & $\begin{array}{l}\text { Inhibitory neuron } \\
\text { subtype (PV) }\end{array}$ & - & + & + \\
\hline
\end{tabular}

(a) Adeno-associated virus (AAV) and lentivirus (LV). Fugu derived sequences are denoted by the prefix " $f$ ".

(b) Length of the promoter used in the virus (bases).

(c) Scoring is from mouse injections to somatosensory cortex.

the PoDG and SGZ (Figures 5A,B). AAV-fNPY injections in the DG labeled cells in PoDG, SGZ and a few scattered cells in GZ (Figures 5C,D). While not quantitative, immunostaining of AAVfSST and AAV-fNPY sections with inhibitory markers PV, SST and NPY confirmed inhibitory labeled cells. Immunostaining, together with little or no expression in the GZ, suggested AAV-fSST and AAV-fNPY may have biased expression towards inhibitory neurons in mouse DG. In contrast and as predicted, AAV-fCAMK drove strong expression both in cells in PoDG and in granule cells (Figures 5E,F).

Deeper injections into mouse thalamus with the AAV-fCAMK vector revealed semi-restrictive expression to the anteroventral nucleus of the thalamus (Figures 5G,H). Contrary to the activity of AAV-fCAMK, in situ hybridization images from the Allen Mouse Brain Atlas (Lein et al., 2007) indicate that CAMK expression is weak in the anteroventral nucleus and strong in other areas of thalamus.

Since CAMK has also been reported to be specifically expressed in the koniocellular layer of primate LGN (Calkins et al., 2005), we also injected this vector in monkey LGN. LGN injections, however showed that AAV-fCAMK did not restrict expression to the koniocellular neurons (data not shown). This evidence indicated that this vector did not recapitulate the natural expression patterns of CAMK in the mouse or monkey thalamus.

\section{AAV-fSST expression strongly favored cortical inhibitory neurons}

Since AAV-fSST showed the highest level of inhibitory neuron specific expression, we sought to quantify the degree of selectivity of this vector. To this end a new viral vector, AAV-fSST-RFP driving RFP rather than GFP, was constructed and injected into the somatosensory cortex of the knock-in mouse line GAD67-GFP $(\Delta$ neo $)$, in which GFP was inserted into the glutamate decarboxylase (GAD67) locus (Tamamaki et al., 2003) (Figure 6). In these mice, almost all of the GFP-positive cells showed GAD67 immunoreactivity in the perikarya or neuropil (Tamamaki et al., 2003) Use of these animals facilitated identification of GABAergic neurons without confounds related to GAD or GABA staining reliability.

Cortical sections from GAD67-GFP mice injected with AAV-fSST-RFP were scored for both GFP and RFP expression. Cells expressing both GFP and RFP were considered inhibitory (Figure 6C). We observed that 93\% $\pm 7 \%, 95 \% \pm 11 \%, 80 \% \pm 13 \%$ and $89 \% \pm 11 \%$ (mean \pm standard deviation) of the cells in layers 

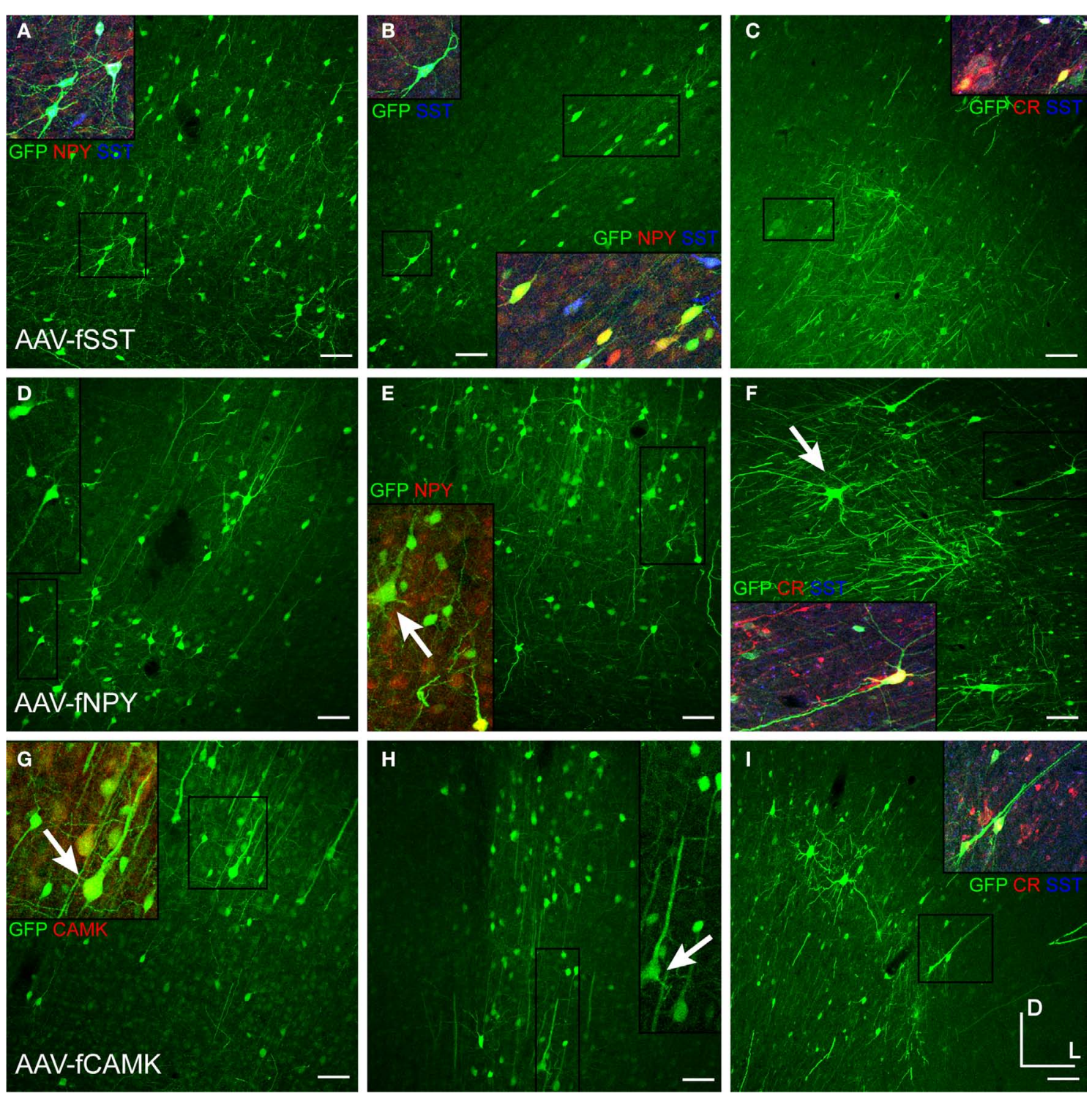

FIGURE 4 | AAV-fSST, AAV-fNPY and AAV-fCAMK expressed in rat and monkey cortex. Viruses expressing GFP were injected in rat somatosensory cortex (A,B, D,E, G,H) and monkey (C,F,I) motor or somatosensory cortex. Molecular identities of some GFP labeled cells of AAV-fSST (A-C)

[(C) - motor cortex], AAV-fNPY (D-F) [(F) - motor cortex] and AAV-fCAMK (G-I) [(I) - somatosensory cortex] were determined by co-labeling with NPY,
CR, SST and CAMK antibodies. Antibodies are indicated in their representative color. Overlap of green and red is yellow; green and blue is purple; green, red and blue is white. Examples of cells consistent with pyramidal morphology are marked with arrows. Boxed inserts are at $2 \times$ magnification. Dorsal (D) and lateral $(L)$ directions for all images are as indicated in (I). Scale bars are $50 \mu \mathrm{m}$.
$2 / 3,4,5$ and 6 were inhibitory, respectively. To interpret the significance of these percentages, we needed to account for the tropism of AAV and the expected chance rate of inhibitory neuron expression. Our previous work (Nathanson et al., 2009) showed that with high titer rAAV2/1, reporter expression in excitatory and inhibitory neurons is proportional to their respective population percentages, but that low titer virus reveals a bias towards inhibitory neurons. To estimate the expected proportion of excitatory/inhibitory neurons transduced by AAV virus of this titer $\left(9.1 \times 10^{9}\right.$ infectious particles $/ \mathrm{ml}$ ) we applied a linear fit to transduction ratios from AAV-hSYN-RFP (data from Nathanson et al., 2009). The expected neurons transduced by the neuronally ubiquitous human synapsin promoter (AAV-hSYN-RFP), are $\sim 68 \%, 77 \%, 50 \%$ and $65 \%$ inhibitory in layers $2 / 3,4,5$ and 6 respectively. These rates reflect a strong but not exclusive bias toward inhibitory neurons, which would have comprised only about $10-20 \%$ of the population by chance (Nathanson et al., 2009). On average, the fSST promoter in AAV preferentially drove expression in $\sim 40 \%$ more inhibitory neurons than would be expected from a promoter producing no bias; the proportion of inhibitory neurons expressing RFP were significantly higher with fSST in AAV than with the hSyn promoter in the same virus and at matched titer ( $\mathrm{p}$ values of $0.0003,0.0223$, $0.0060,0.0595$ for layers $2 / 3,4,5$ and 6 for a one sample $t$-test to the estimated ratios). 

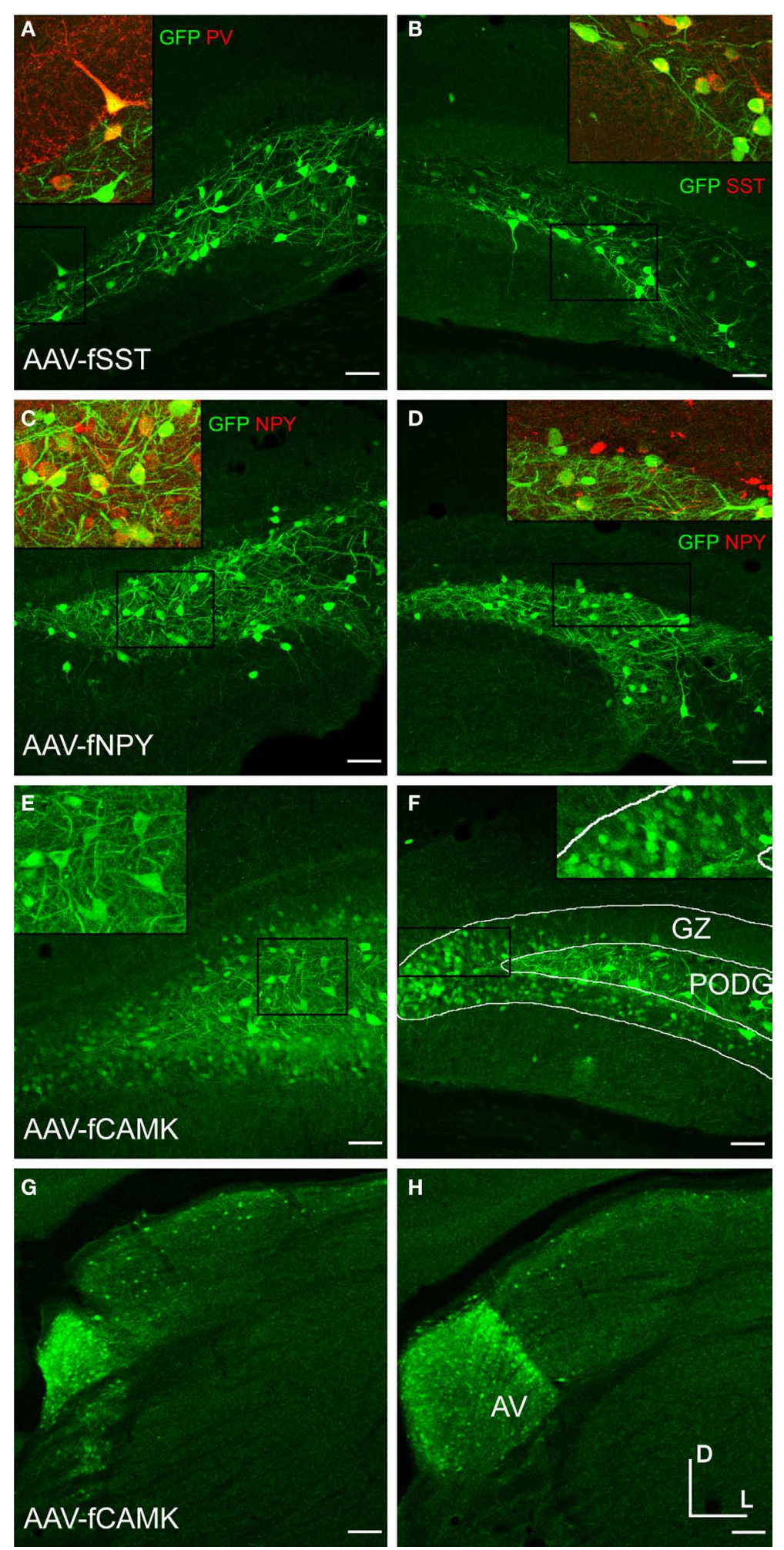

FIGURE 5 | Fugu promoters in AAV expressed in mouse dentate gyrus (DG) and thalamus. Fugu promoters in AAV drove GFP expression in subcortical areas of the DG and thalamus. Virus expression is shown in green [AAV-fSST - (A,B); AAV-fNPY - (C,D); AAV-fCAMK - (E-H)]. Subcortical anatomical regions - granule cell layer (GZ) and polymorphic layer (PoDG) shown in (A-F), are described in (F). The anteroventral nucleus of the thalamus (AV) shown in $(\mathbf{G})$ and $\mathbf{( H )}$, is described in $(\mathbf{H})$. Cell-type markers PV, SST and NPY are shown in red. Green and red overlap is yellow. Boxed inserts are at $2 \times$

magnification. Dorsal (D) and lateral $(L)$ directions for all images are as indicated in (H). Scale bars are $50 \mu \mathrm{m}$. 

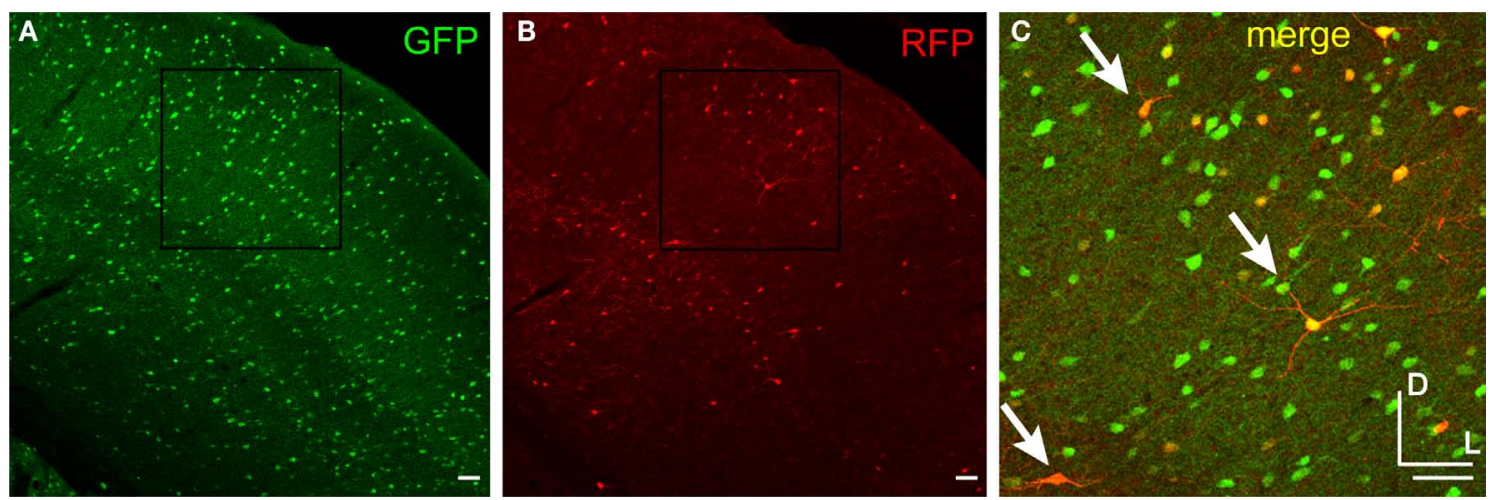

FIGURE 6 |AAV-fSST predominately labeled inhibitory neurons in mouse cortex. Mouse cortex with inhibitory neurons expressing GFP under the control of the GAD67 promoter (A) was injected with AAV-fSST expressing RFP (B). Panel (C) is the overlap of the boxed region in
(A) and (B). Green and red overlap is yellow. Examples of cells with green and red overlapping label are indicated by arrows. Dorsal (D) and lateral $(\mathrm{L})$ directions for all images are as indicated in (C). Scale bars are $50 \mu \mathrm{m}$

\section{Fugu promoters failed to generate inhibitory neuron subtype specific expression}

The expression of fugu promoters in AAV in inhibitory neuron subtypes was quantified in mouse cortex by identifying cells expressing GFP from viral vector that were co-labeled with antibodies for CR, PV, SST, VIP and NPY. Cell-type specific antibody-labeled cells were counted in regions defined by the virus spread. Figure 7 shows an example of cell-type antibody and GFP label in mouse cortex injected with AAV-fSST (GFP).

Virus expression in each cell-type was quantified by dividing the number of double labeled cells (GFP and cell-type antibody label) by the total number of cell-type antibody labeled cells in the virus labeled regions. First, to identify a baseline level of transduction of AAV in inhibitory neuron subtypes, expression from the human synapsin (hSYN) promoter was quantified. Even with the high titer AAV-hSYN virus $\left(4.9 \times 10^{10}\right.$ infectious particles $\left./ \mathrm{ml}\right)$ (Nathanson et al., 2009), not every inhibitory neuron expressed the transgene, presumably because many neurons were not infected. In the injected region of mouse somatosensory cortex, AAV-hSYN labeled $72 \%, 79 \%, 70 \%, 55 \%$ and $97 \%$ of CR, PV, SST, VIP and NPY cells, respectively (Figure 8). While the numbers of cells were small, these numbers suggest that some inhibitory cell-types were transduced more efficiently than others. For example, almost all of the NPY+ cells, but only about half of the VIP+ cells were labeled.

We observed that AAV-fSST, AAV-fNPY, AAV-fPV and AAV-fCR expressed in all identified inhibitory cell-types, demonstrating that none of the promoters restricted expression to a particular inhibitory neuron subtype (Figure 8). AAV-fSST and AAV-fNPY promoters did not show significant differences in inhibitory neuron subtype expression compared to the expression of high titer AAV-hSYN. Interestingly however, AAV-fPV and AAV-fCR showed a significant reduction in $\mathrm{PV}+$ and CR+ cells, respectively $(t$-test $-p=0.001$ and $p=0.003)$, the very types of cells that their promoters were aimed to target.

\section{Fugu promoters in lentivirus drove expression in excitatory neurons}

In comparison to AAV, a GFP expressing lentivirus ( $\mathrm{LV}$ ) vector can accommodate longer promoter sequences up to $\sim 6.6 \mathrm{~kb}$. Larger regions of the fugu PV, CR, SST and NPY promoter sequences, encompassing up to the entire $5^{\prime}$ intergenic region were cloned into lentivirus driving GFP (Figure 1). We previously found that following cortical injections, LV labeled large numbers of excitatory neurons and glia, but it did not label large numbers of inhibitory neurons (Nathanson et al., 2009). These results suggested that LV would provide a skewed, but more sensitive assay than AAV to assess the ability of promoters to express in excitatory neurons.

Injection into mouse somatosensory cortex revealed that all fugu promoters in LV drove gene expression (Figure 8, Table 1). LV-fPV and LV-fSST expression signals were the strongest and LV-fNPY and LV-fCR were the weakest (Figure 9). All of these promoters in LV appeared to restrict expression to neurons versus glial cells. Morphological observations indicated that all fugu promoters in LV drove expression in a higher proportion of excitatory cells than they did in AAV. In LV-fPV, the labeled cells were densely packed, consistent with large numbers of dense pyramidal neurons (Figures 9A,B). Cell label density was more scattered for LV-fSST, but cell density was still higher than would be expected if all the cells were inhibitory. Consistent with the greater cell density of excitatory neurons, we also observed a few cells with pyramidal neuron morphology (Figures 9C,D). Expression of LV-fNPY and LV-fCR vectors was restricted to only a handful of cells (Figures 9E,F). In contrast to AAV-fCR, LV-fCR did not label any glia. Co-label with inhibitory markers PV, CR, SST, and VIP indicated that at least a few cells labeled by each virus were inhibitory (data not shown). Promoter activity in LV was largely in agreement with the promoter activity in AAV, but LV expression shifted toward excitatory expression consistent with the expected differences due to viral tropism (Nathanson et al., 2009).

\section{MAMMALIAN PROMOTERS}

Promoter sequences were isolated from mouse and human DNA sequences for genes associated with known cell-types (Table 2). Prefixes denote mouse ( $\mathrm{m}$ ) and human $(\mathrm{h})$ derived promoter sequences. The promoters of mouse glutamate decarboxylase 2 targeting all inhibitory neurons (LV-mGAD2) and mouse somatostatin (LV-mSST) were cloned into the LV vector. We also constructed GFP or RFP expressing $A A V$ vectors with the promoters of platelet-derived growth factor receptor, alpha polypeptide (AAV-hPDGFRA) - targeting 

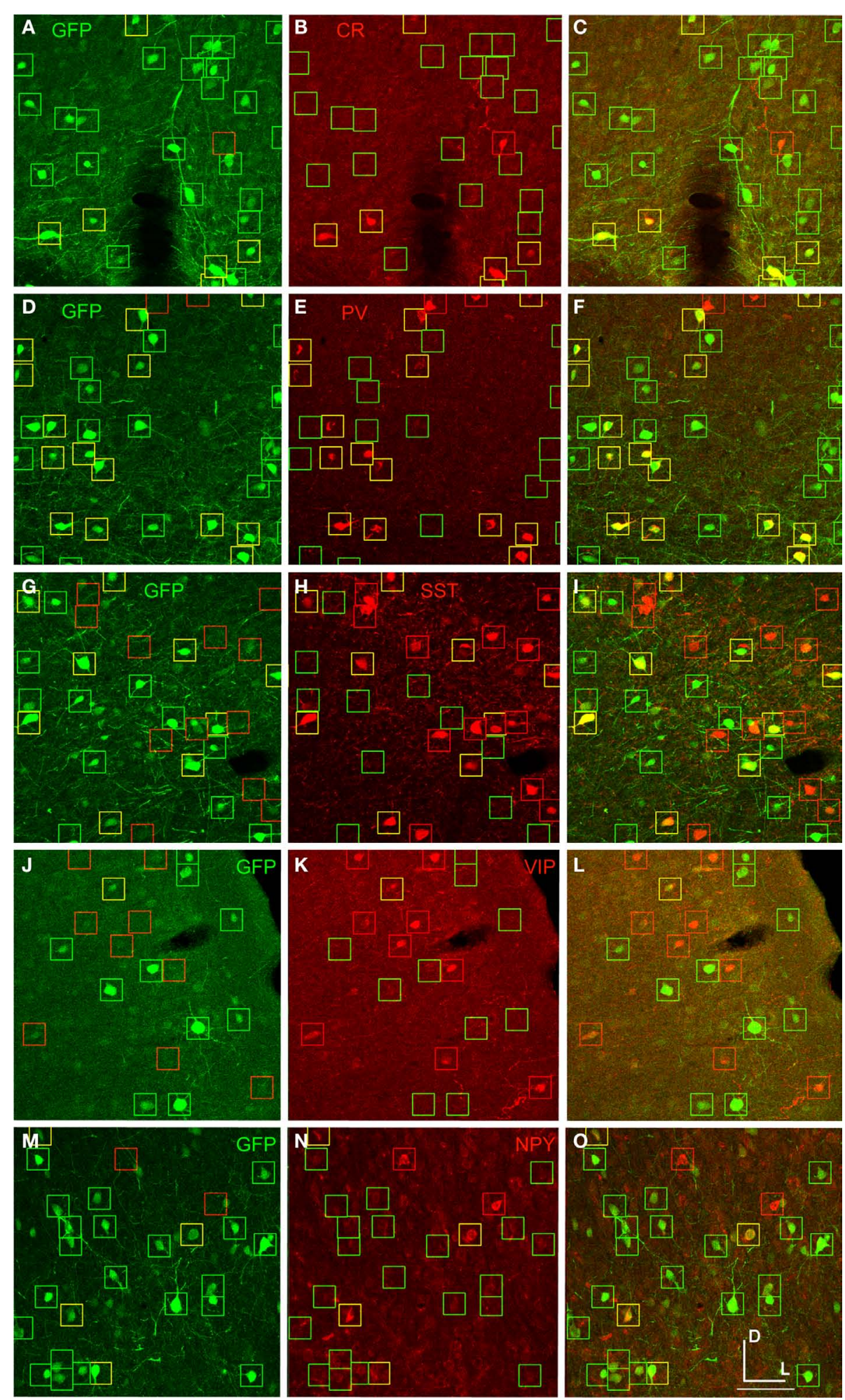

FIGURE 7 |AAV-fSST expression co-labeled with CR, PV, SST, VIP and NPY antibodies. AAV-fSST-GFP expression in mouse somatosensory cortex is shown in the left column (A,D,G,J,M). Cell-type specific antibody labeling in the corresponding sections are shown in the middle column $(\mathbf{B}, \mathbf{E}, \mathbf{H}, \mathbf{K}, \mathbf{N})$. Overlaps of the left and middle columns are shown in the right column $(\mathbf{C}, \mathbf{F}, \mathbf{I}, \mathbf{L}, \mathbf{O})$ - calretinin $[\mathrm{CR}-(\mathbf{B}, \mathbf{C})]$, parvalbumin $[\mathrm{PV}-\mathbf{( E , F ) ] , ~ s o m a t o s t a t i n ~}$
$[S S T-(\mathbf{H}, \mathbf{J})]$, vasoactive intestinal polypeptide $[\mathrm{VIP}-\mathbf{( K , L )}]$ and neuropeptide $Y$ [NPY - $(\mathbf{N}, \mathbf{O})]$. Cells that have GFP label only are marked with green boxes.

Cells that have cell-type specific antibody label only are marked with red boxes. Cells that are co-labeled are marked with yellow boxes. Dorsal (D) and lateral (L) directions for all images are as indicated in $(\mathbf{O})$. The scale bar for all images, shown in (0), is $50 \mu \mathrm{m}$. 


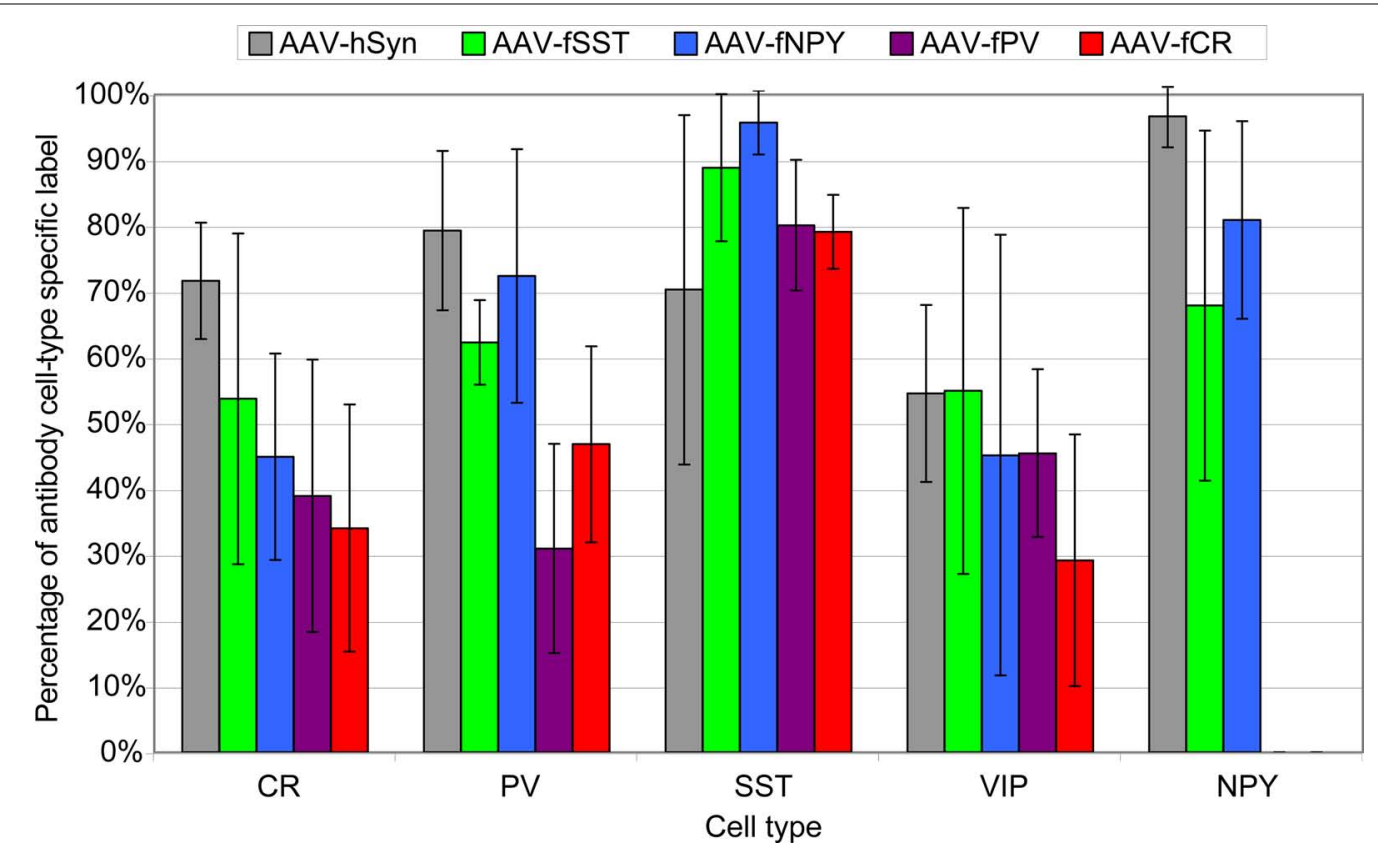

FIGURE 8 | Percentage of virus label in inhibitory neuron subtypes. Viruses expressing GFP were injected into mouse somatosensory cortex and stained for inhibitory neuron markers calretinin (CR), parvalbumin (PV), somatostatin (SST), vasoactive intestinal polypeptide (VIP) and neuropeptide Y (NPY).

Percentages were calculated by dividing the number of co-labeled cells (GFP and cell-type specific antibody) by the total number of antibody labeled cells in the injected region. The percentages reflect the combined labeling in cortical layers $2 / 3-6$ and the standard deviations show the labeling distributions treating each section as an independent observation. Sections were counted from a single animal for AAV-fPV, and from three animals for all others. NPY label was not counted for AAV-fPV and AAV-fCR. At least 170 cells were counted for each vector/antibody combination (see Materials and Methods).
SST inhibitory neuron populations; and of A930038C07Rik (AAVmA93) - based on characteristic inhibitory neuron expression patterns observed in the Allen Mouse Brain Atlas (Lein et al., 2007) and targeting an unknown subpopulation of inhibitory neurons.

Next, we also used microarray data from somatosensory and cingulate cortices compiled by Sugino et al. (2006) to identify genes co-expressed within one of the inhibitory neuron subtypes G42 (PV), GIN (SST) or G30 (VIP), and not expressed in excitatory neurons. A detailed description of the rationale for choosing these genes and promoter design are provided in Material and Methods. First we analyzed the microarray data for genes that showed more than 3-fold enrichment for a single inhibitory neuron cell-type (see Table $\mathbf{S 1}$ in Supplementary Material). Because microarray data is prone to false positives, these genes were then checked in the Allen Mouse Brain Atlas (Lein et al., 2007) for a pattern of scattered expression, consistent with inhibitory neuron distribution. For each selected gene, upstream and $5^{\prime}$ UTR gene regions were analyzed for the presence of putative TFBSs that were conserved across multiple mammalian species. Conserved TFBSs enriched in a group of co-expressed genes were hypothesized to be determinant regulatory elements for a specific cell-type (see Tables S2-4 in Supplementary Material). In search of promoter sequences most likely to drive cell-type specific expression we chose the ones with the maximum number of cell-type specific regulatory elements and a minimum number of elements characteristic of the other inhibitory cell-types. Using this strategy, AAV vectors expressing RFP were designed with regulatory elements derived from the human genes, aimed at targeting each of the three non-overlapping interneuron cell-types: for SST cell-type - glutamate receptor, metabotropic 1 (AAV-hGRM1), c-type natriuretic peptide precursor (AAV-hNPPC); for PV cell-type - adrenomedullin (AAV-hADM), type 2 lactosamine alpha-2,3-sialyltransferase (AAV-hST3GAL6); for VIP cell-type - ras responsive element binding protein 1 (AAVhRREB1), deiodinase, iodothyronine, type II (AAV-hDIO2), nuclear receptor subfamily 2 , group F, member 2 (AAV-hNR2F2).

Injections of viruses into the cortex of mice or rats revealed that only some of the mammalian promoters drove transgene expression (Table 2) and only AAV-mA93 showed some cell-type specificity. Morphologies of cells labeled by LV-mGAD2, LV-mSST and AAVhPDGFRA indicated that these vectors expressed in some excitatory pyramidal neurons (Figures 10A-C). LV-mSST also drove expression in some glia (Figure 10B). AAV-hNPPC, AAV-hNR2F2 and AAV-hDIO2 failed to label any cells in mouse cortex. GAD67-GFP knock-in mice injected with viruses expressing RFP are shown in Figure 11. RFP+ cells that co-labeled with GFP were inhibitory. The sections were also stained with parvalbumin (PV) antibody. AAVhADM drove expression in only a few cells, all of which appeared to be glia (Figures 11A-D). Expression of AAV-hGRM1 (Figures 11E-H), AAV-hRREB1 (Figures 11I-L) and AAV-hST3GAL6 (Figures 11M-P) drove expression in both excitatory and inhibitory neurons. In contrast, AAV-mA93 (Figures 11Q-T) did not appear to label any excitatory neurons, but strongly labeled inhibitory neurons and glia. AAV-hGRM1,AAV-hRREB1,AAV-hST3GAL6 and AAV-mA93 labeled inhibitory neurons that were PV+ and PV-, indicating that none of these promoters drove inhibitory neuron subtype specific expression. Interestingly, most of the PV+ cells labeled by AAV-hRREB1 displayed pyramidal morphology. Since some 

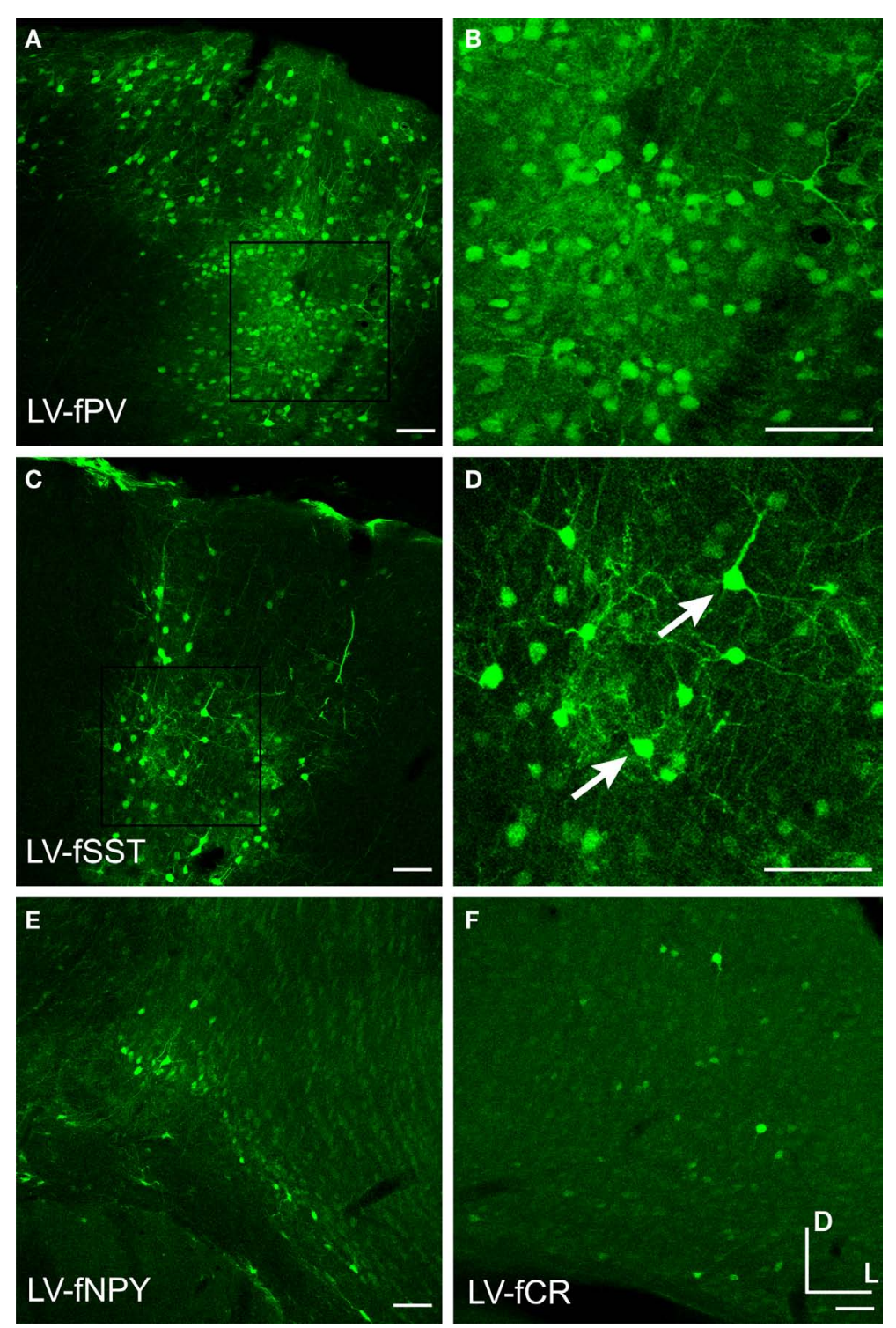

FIGURE 9 | Fugu promoters in LV drove expression in large numbers of excitatory neurons. Fugu promoters in LV expressing GFP were injected into mouse somatosensory cortex - LV-fPV (A,B), LV-fSST (C,D), LV-fNPY (E), LV-fCR
(F). Panels (B) and (D) are magnified versions of the boxed regions of (A) and (C), respectively. Arrows mark excitatory pyramidal neurons. Dorsal (D) and lateral (L) directions for all images are as indicated in (F). Scale bars are $50 \mu \mathrm{m}$. pyramidal cells have been shown to express low levels of PV protein in monkey (Preuss and Kaas, 1996) and mRNA in mouse (Sugino et al., 2006), it is possible AAV-hRREB1 largely restricted expression to PV+ cell-types, both excitatory and inhibitory. Altogether, many of the mammalian promoters failed to express in the cortex, and those that drove expression did not appear to restrict expression to inhibitory neurons better than the fugu promoter sequences.

\section{TRANSCRIPTION FACTOR BINDING SITE (TFBS) ASSEMBLED PROMOTERS}

As an alternative strategy to drive cell-type specific expression in inhibitory neurons, we created artificial promoter constructs assembled with known transcription factor binding sites DR1 (Okuno et al., 2001) or E1.1 (Scardigli et al., 2003). The PPAR $\gamma / \operatorname{RXR} \alpha$ (peroxisome-proliferator-activated receptor gamma/retinoid X receptor alpha) transcription factor complex (Okuno et al., 2001) binds to the 24-bp DR1 motif. According to Sugino et al.'s (2006) microarray data, PPAR $\gamma$ is enriched in the PV+ population and RXR $\alpha$ is expressed at high levels in SST+ and VIP+ inhibitory populations, and at low levels in the PV+ population. Since PPAR $\gamma / \mathrm{RXR} \alpha$ complex binds to DR1 in the presence of high molar ratios of PPAR $\gamma$ to RXR $\alpha$ (Okuno et al., 2001), we expected positive activity of DR1 in PV+ cells.

The E1.1 enhancer element contains 11 nucleotides of the 16-nucleotide PAX6 consensus binding sequence and reportedly restricted expression in Ngn2 positive cells by binding PAX6 in the mouse spinal cord and telencephalon (Scardigli et al., 2003). Since Sugino et al.'s (2006) data suggested that PAX6 is enriched in the VIP+ inhibitory population, we expected positive activity of E1.1 in VIP+ cells. 
Table 2 |AAV and LV vectors with mammalian promoters.

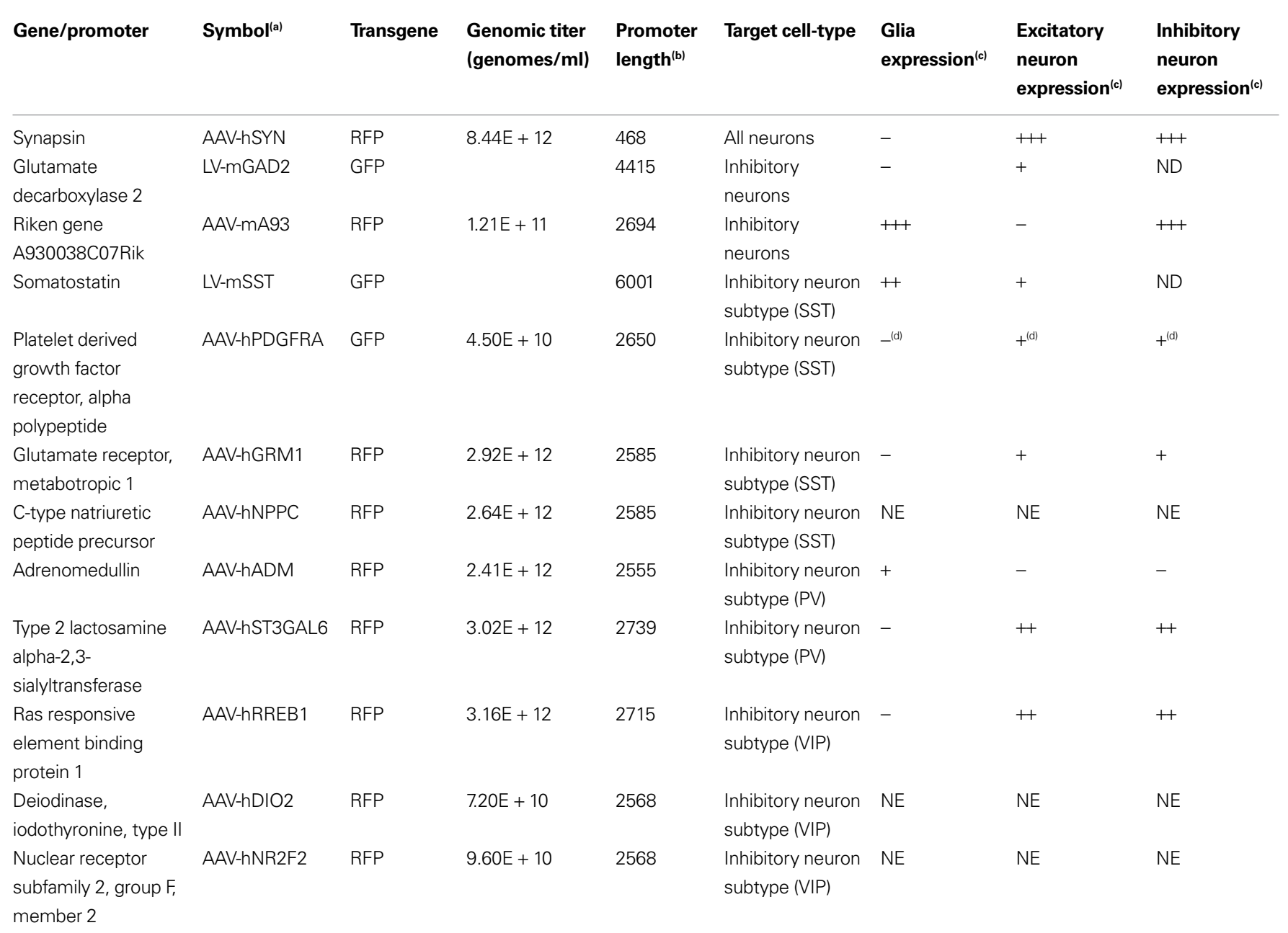

(a) Adeno-associated virus (AAV) and lentivirus (LV). Mouse and human derived sequences are denoted by the prefix " $m$ " and " $h$," respectively.

(b) Length of the promoter used in the virus (bases).

(c) Scoring is relative to other viruses. NE = no expression. $N D=$ not determined.

(a) Scoring is generally from mouse injections. Rat scoring is indicated.
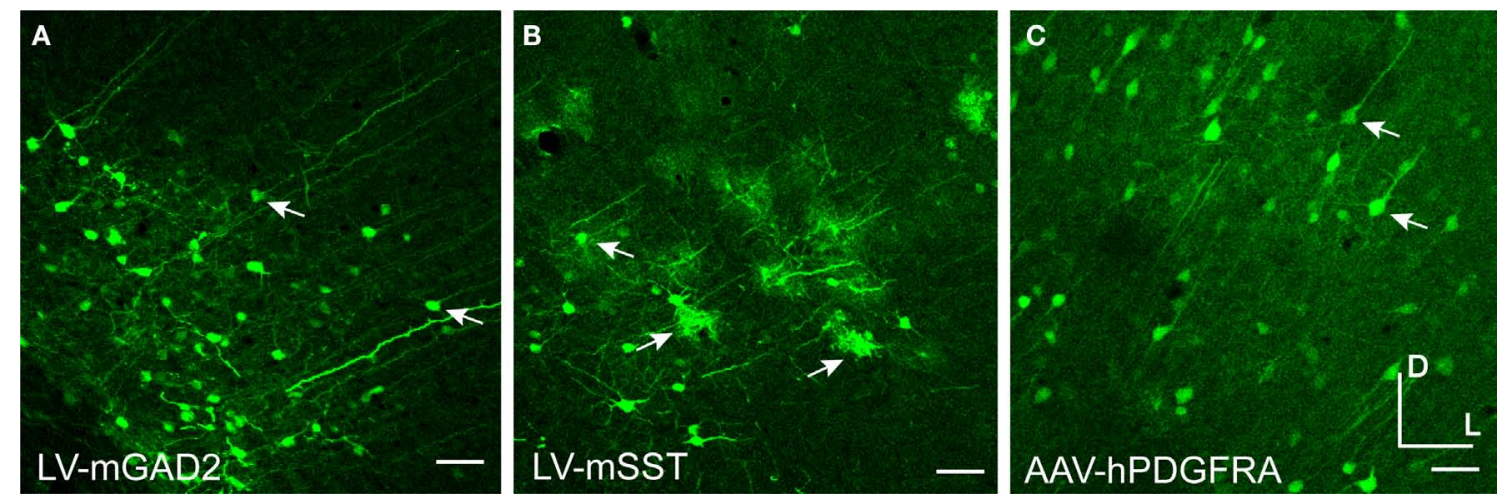

FIGURE 10 | Mammalian promoters drove expression in rodent cortex. Mice were injected with LV expressing GFP driven by mouse promoter sequences for glutamate decarboxylase 2 [LV-mGAD2 - (A)] and somatostatin [LV-mSST - (B)]. Rats were injected with AAV expressing GFP driven by the human promoter sequence for platelet-derived growth factor receptor, alpha polypeptide [AAV-hPDGFRA - (C)]. Rightward pointing arrows mark glia and leftward pointing arrows mark excitatory pyramidal neurons. Dorsal and lateral directions for all images are as indicated in (C). Scale bars are $50 \mu \mathrm{m}$. 

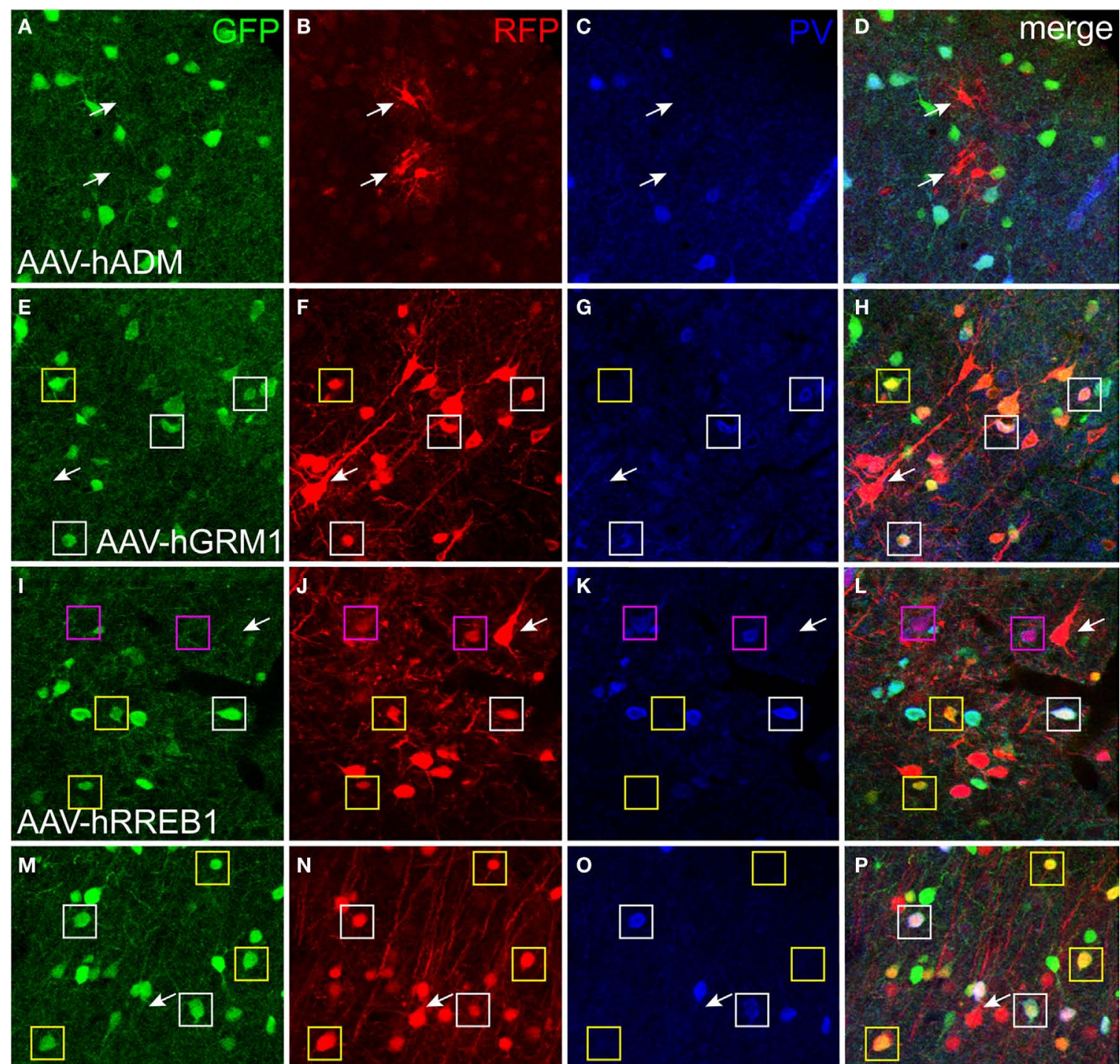

\section{AAV-hST3GAL 6}
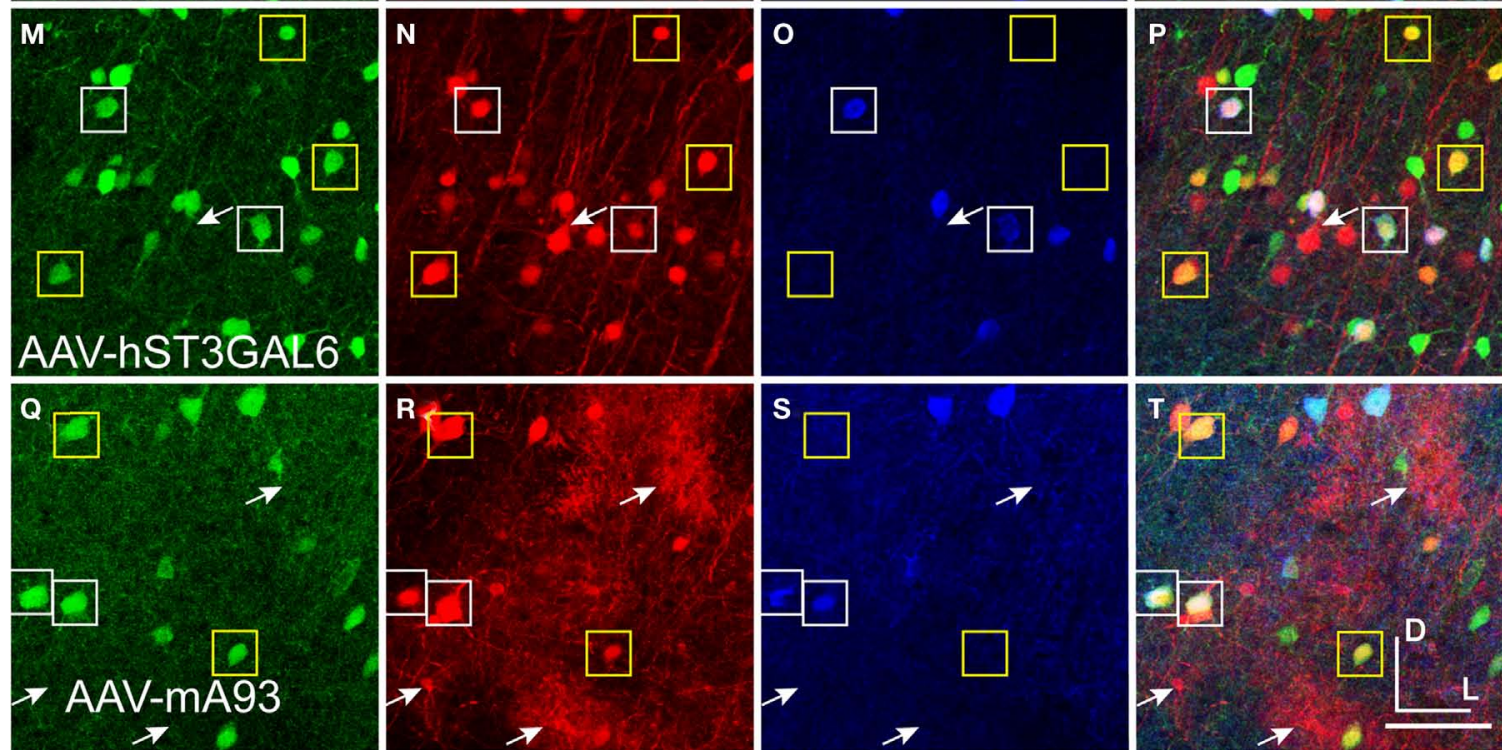

FIGURE 11 | Mammalian conservedTFBS promoters drove expression in mouse brain. GAD67-GFP knock-in mice were injected with AAV expressing RFP driven by promoter sequences with presumed cell-type specific regulatory elements. Images in each row are images of the same section. Green label in the first column on the left $(\mathbf{A}, \mathbf{E}, \mathbf{I}, \mathbf{M}, \mathbf{Q})$ is inhibitory neuron specific GAD67-GFP expression. Red label in the second column from the left (B,F,J,N,R) is RFP virus expression. Blue label in the third column from the left $(\mathbf{C}, \mathbf{G}, \mathbf{K}, \mathbf{O}, \mathbf{S})$ is parvalbumin (PV) antibody label. The right column $(\mathbf{D}, \mathbf{H}, \mathbf{L}, \mathbf{P}, \mathbf{T})$ is the merge of the previous columns. Overlap of green and red is yellow; green and blue is teal; red and blue is purple; green, red and blue is white. Viral vectors were as follows: adrenomedullin [AAV-hADM - (A-D)], glutamate receptor, metabotropic 1 [AAV-hGRM1 - (E-H)], ras responsive element binding protein 1 [AAV-hRREB1 (I-L)], type 2 lactosamine alpha-2,3-sialyltransferase [AAV-hST3GAL6 - (M-P)] and riken gene A930038C07Rik [AAV-mA93 - (Q-T)]. Examples of double and triple labeled cells are marked with boxes. The color of the box matches the cell overlap color. Rightward pointing arrows mark glia and leftward pointing arrows mark excitatory pyramidal neurons. Dorsal (D) and lateral $(L)$ directions for all images are as indicated in (T). Scale bars are $50 \mu \mathrm{m}$ 
The neuron restrictive silencing element (NRSE) is a 21- to 23-bp DNA transcription factor binding site found in many neuronal genes. The neuron restrictive silencing factor (NRSF) silences neuronal genes in non-neuronal cells by binding to NRSE through the association of the histone deacetylase complex (Huang et al., 1999; Naruse et al., 1999) or methyl-CpG-binding protein 2 (Lunyak et al., 2002). We expected the incorporation of this negative regulator of transcription to restrict promoter activity to neuronal cells.

Three composite regulatory element (CRE) promoters were created by combining DR1 or E1.1 motifs with or without NRSE and a minimal CMV promoter (see Table 3 and Materials and Methods). Mice and rats were injected with vectors expressing either GFP or RFP under the control of these CRE promoters. AAV-DR1-NRSE (RFP) expressed in only a few cells, most of which appeared to be glia (Figure 12). In contrast, AAV-E1.1 and AAV-E1.1-NRSE expressed strongly and only in a handful of cells scattered over up to $\sim 200 \mu \mathrm{m}$ from the injection. AAV-E1.1NRSE (RFP) expression is shown in Figure 13. We have observed other viral vectors driving expression at similarly far distances, but the density of cell expression for AAV-E1.1 and AAV-E1.1NRSE were sparse, suggesting that these promoters restricted expression to only some cell-types. Most of the RFP labeled cells from AAV-E1.1-NRSE co-labeled with GAD67-GFP, indicating this vector predominantly drove expression in inhibitory neurons (Figures 13A-D,G,H), but a few glial cells also expressed RFP. While the addition of the NRSE to AAV-E1.1 appeared to reduce glia expression, probably the single copy of NRSE in AAV-E1.1NRSE was not sufficient to completely restrict expression to neurons. Notably, in mice very few RFP labeled cells co-labeled with parvalbumin (PV) antibody, and expression in these cells was faint (Figures 13E-H). Thus, in mice AAV-E1.1-NRSE largely restricted expression to non-parvalbumin inhibitory neurons. Interestingly however, when rats were injected with AAV-E1.1 (without NRSE), transgene co-labeled with antibodies to inhibitory neuron subtypes (CR, SST and VIP), and PV (data not shown), suggesting that the PAX6 transcription factor may be expressed differently in inhibitory neurons of mouse and rat.

\section{DISCUSSION}

In this study we targeted inhibitory neuron subtype specific expression using promoter sequences in viral vectors. While none of the promoters tested were capable of restricting expression to inhibitory

Table 3 | AAV vectors with composite regulatory element (CRE) promoters.

\begin{tabular}{|c|c|c|c|c|c|c|c|c|}
\hline Gene/promoter & Symbol $^{(a)}$ & Transgene & $\begin{array}{l}\text { Genomic titer } \\
\text { (genomes/ml) }\end{array}$ & $\begin{array}{l}\text { Promoter } \\
\text { length }^{(\mathbf{b})}\end{array}$ & Target cell-type & $\begin{array}{l}\text { Glia } \\
\text { expression }\end{array}$ & $\begin{array}{l}\text { Excitatory } \\
\text { neuron } \\
\text { expression }\end{array}$ & $\begin{array}{l}\text { Inhibitory } \\
\text { neuron } \\
\text { expression }\end{array}$ \\
\hline $\begin{array}{l}\text { PPARyDR1 } \\
\text { binding site with } \\
\text { NRSE }\end{array}$ & AAV-DR1-NRSE & RFP & $1.66 E+12$ & 121 & $\begin{array}{l}\text { Inhibitory neuron } \\
\text { subtype (PV) }\end{array}$ & + & - & - \\
\hline $\begin{array}{l}\text { E1.1 binding } \\
\text { sites }\end{array}$ & AAV-E1.1 & GFP & $9.60 E+10$ & 214 & $\begin{array}{l}\text { Inhibitory neuron } \\
\text { subtype (VIP) }\end{array}$ & $+^{(c)}$ & $--^{(c)}$ & $+^{(c)}$ \\
\hline $\begin{array}{l}\text { E1.1 binding } \\
\text { sites with NRSE }\end{array}$ & AAV-E1.1-NRSE & RFP & $1.53 E+12$ & 239 & $\begin{array}{l}\text { Inhibitory neuron } \\
\text { subtype (VIP) }\end{array}$ & + & - & + \\
\hline
\end{tabular}

(a) Adeno-associated virus (AAV).

(b) Length of the promoter used in the virus (bases).

(c) Scoring is generally from mouse injections. Rat scoring is indicated.
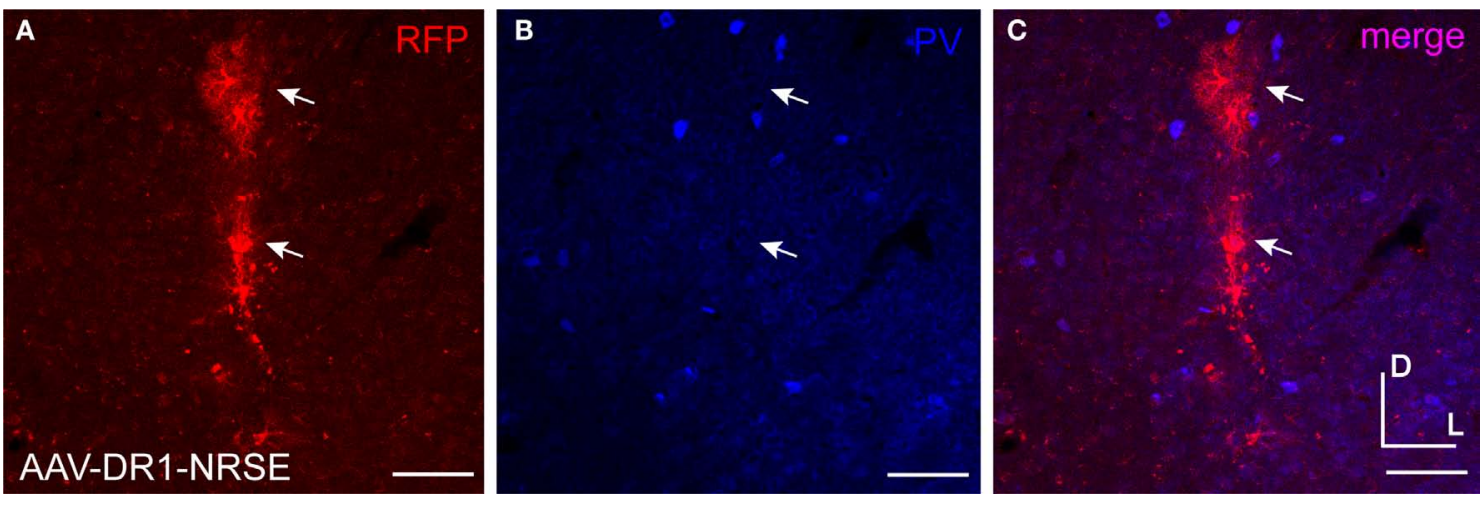

FIGURE 12 |AAV-DR1-NRSE drove expression in only a few cells. AAV driven by the composite regulatory element promoter containing DR1 and NRSE motifs (AAV-DR1-NRSE) was injected into mouse somatosensory cortex. Expression of the RFP AAV transgene is shown in red $(\mathbf{A})$ and $\mathrm{PV}$ antibody staining in blue (B). Overlap of red and blue images is shown in (C). Glia are marked with arrows. Dorsal (D) and lateral $(\mathrm{L})$ directions for all images are as indicated in (C). Scale bars are $50 \mu \mathrm{m}$. 

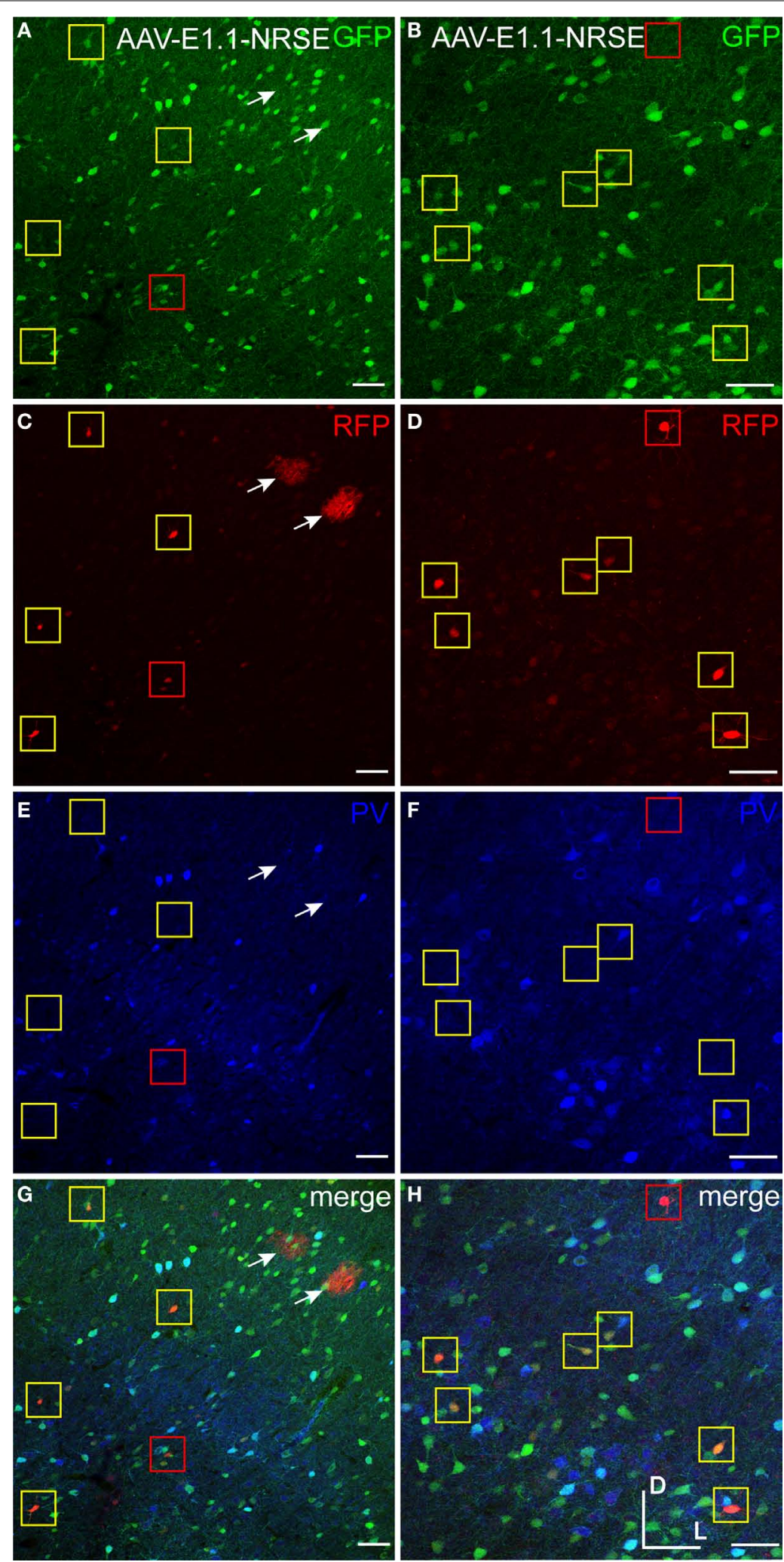

FIGURE 13 |AAV-E1.1-NRSE drove strong expression in a scattered population of cells. AAV with a promoter containing the E1.1 and NRSE motifs (AAV-E1.1-NRSE) was injected into the somatosensory cortex of GAD67-GFP knock-in mice $\mathbf{( A , B , G , H ) . ~ E x p r e s s i o n ~ o f ~ t h e ~ R F P ~ A A V ~ t r a n s g e n e ~ i s ~ s h o w n ~ i n ~ r e d ~}$
$(\mathbf{C}, \mathbf{D}, \mathbf{G}, \mathbf{H})$ and parvalbumin (PV) antibody staining in blue (E-H). Green and red is yellow. The color of the box matches the cell overlap color. Glia are marked with arrows. Dorsal (D) and lateral $(\mathrm{L})$ directions for all images are as indicated in (H) Scale bars are $50 \mu \mathrm{m}$. 
neuron subtypes, AAV-fSST largely restricted expression to inhibitory neurons both in mouse and in rat. Therefore the SST fugu promoter might be a useful vector in rodent studies targeting the inhibitory neuron class as a whole. In addition, the expression shown by the artificial promoter construct AAV-E1.1-NRSE demonstrates that this vector might be useful for studies targeting SST and VIP, but not PV immunoreactive inhibitory neurons in mice.

In the search for inhibitory neuron specific promoters, we showed that $\mathrm{rAAV} 2 / 1$ is a suitable vector for testing promoter sequences in mouse cortex. Label from AAV-hSYN (and also the fugu vectors in AAV), overlapped with the classical inhibitory neuron markers CR, NPY, SST, PV and VIP. While nearly all of the NPY, and the majority of CR, SST and PV immunoreactive cells were labeled using high titer $\mathrm{rAAV} 2 / 1$, only about half of the VIP immunoreactive cells were labeled. Since we previously observed that labeling efficiency of rAAV2/1 can be biased towards inhibitory neurons depending on the titer of the virus (Nathanson et al., 2009), we might also suspect that lower titers of virus could result in even fewer proportions of VIP labeled cells. Therefore, one must be cautious in interpreting quantitative results of promoter activity of AAV vectors in inhibitory neurons. This caution is relevant to all viral vectors, and viral tropism should be considered by first using promoters capable of driving the most ubiquitous expression.

In this study we showed that all of the fugu promoters tested drove expression in the mammalian brain. Some of the tested fugu promoter sequences largely restrict expression to inhibitory GABAergic neurons (fSST and fNPY); some promoters limit expression to neuronal cells in general; and others drive expresson in glia as well. None restricted expression to inhibitory neuron subtypes. One possibility for the lack of specificity is that the tested fugu sequences lack negative regulatory signals which might be located in sequences further $5^{\prime}$ of the cloned region, in $5^{\prime}$ UTRs, in introns, or in $3^{\prime}$ intergenic regions of the genes of interest. Alternatively, it is possible that inhibitory neuron cell-type specific gene expression cannot easily be duplicated in adult cells due to epigenetic changes such as CpG methylation. Also, the fact that none of the fugu promoters restricted expression to a particular cell-type may suggest that the intricacies of inhibitory cell-type specific regulation may not be highly conserved among fish and mammals. Indeed, recent work has shown that inhibitory neuron expression can differ even between the small evolutionary distances between different rodent species. Xu et al. (2006) has shown that unlike in rat, CR expresses in a subset of SST+ cells in mice which are otherwise similar across species in both morphology and intrinsic physiology. Since even simple base pair substitutions and changes in distances between regulatory elements can change gene expression (RodriguezTrelles et al., 2003), complex regulatory environments involving many interacting factors may not be commonly shared between evolutionarily distant species. Small genetic differences can have a profound effect if the regions of difference are important. King and Wilson (1975), among others, have suggested that the profound phenotypic differences between humans and chimpanzees which share more than $98.5 \%$ nucleotide identity (Ebersberger et al., 2002), are likely a result of differences in the regulatory regions of genes. Indeed, $\sim 15 \%$ of CpG sites differ between human and chimpanzee (Ebersberger et al., 2002). Therefore, the ability for the same regulatory region to function across multiple species may be more a rarity than a rule, and those that are evolutionarily conserved are likely to be concentrated among genes that are developmentally indispensable. Indeed, the majority of evolutionarily conserved sequences between fugu and mammals have been found in the proximity of genes encoding transcription factors and/or genes expressed in early developmental stages (Woolfe et al., 2005). Regulation of the selected genes in inhibitory neuron subtypes may not have these evolutionary constraints. For example, expression of one calcium binding protein such as PV, might be replaced by another, such as calbindin.

As described, a collection of promoters drove expression in neurons, but not glia (fSST, fNPY, fPV, fCAMK, hPDGRFA, hGRM1, hST3GAL6, hRREB1). Likewise, a set of the promoters preferentially drove expression in inhibitory neurons with minimal excitatory neuron expression (fNPY, fSST, mA93, E1.1-NRSE). These results suggest that the regulatory mechanisms responsible for driving expression in the broader cell-type classes of inhibitory neurons, excitatory neurons or glia, may be relatively simple and shared between species. Nevertheless, identification of these regulatory mechanisms between inhibitory and excitatory neurons has remained elusive. In contrast to inhibitory neurons as a whole, our inability to achieve subtype specific expression in inhibitory neurons suggests subtype regulatory mechanisms are quite complex. To this point, even the simple E1.1-NRSE composite regulatory element drove expression in multiple inhibitory neuron subtypes. These results suggest that complex regulatory environments including antagonistic repressors may be needed to restrict expression to inhibitory neuron subtypes.

Lentiviral vectors containing fCR, fSST, fNPY and fPV promoters were also tested. These promoters were larger than in AAV, encompassing the promoters tested in $\mathrm{AAV}$, and in some cases including the entire $5^{\prime}$ intergenic region. We consistently observed many more excitatory neurons in LV than in AAV injected brains among corresponding promoters. In a previous study (Nathanson et al., 2009) we demonstrated that AAV preferentially drove expression in inhibitory neurons relative to excitatory neurons. With this understanding, the consistent expression differences between corresponding promoters in our current study supports the possibility that viral vector tropism might have contributed more to increased LV excitatory neuron expression than did the differences in composition between the corresponding AAV and LV promoter versions. Nevertheless, AAV-fCR drove expression in glia while LV-fCR did not. Since both AAV and LV efficiently transduce glia, these results suggest differences in the content of these promoters were responsible for these observed differences in glia expression.

None of the mammalian promoters taken from the group of coexpressed genes showed inhibitory neuron specificity. The computational analysis did not resolve the necessary elements for inhibitory neuron cell type specificity. Yet, we might have improved inhibitory versus excitatory neuron specificity if we had contrasted promoter sequences from the inhibitory neuron cell-type groups with those of excitatory neurons, rather than just between inhibitory neuron cell-type groups. In addition, one major limitation towards achieving inhibitory neuron cell-type specific regulation was the relatively small number of genes for which we could reasonably presume to be co-expressed in each of the cell-type groups. Also, the variability of genes within each inhibitory neuron subtype cluster, as evident 
by the different patterns of expression seen in various regions of the mouse brain, indicate that many of the co-expressed genes are not associated or co-regulated in the same cell-types outside of cortex. Given these limitations, it was not entirely unexpected that we did not find TFBSs which were strongly enriched in one celltype and absent from the others. Rather than searching for determinant cell-type specific factors, we were resolved to find factors largely enriched in a group. To this end, the analysis revolved around establishing ratios that were out of balance between cell-types (see Tables S2-4 in Supplementary Material). If however our dataset truly consisted of co-expressed genes and the regulatory environments were not too complex, we might expect that an analysis of a limited and noisy dataset could succeed in identifying common regulatory elements. However, together with the lack of cell-type specificity of the fugu promoters, these results suggest that regulation of inhibitory neuron cell-type specificity is likely complex and might also involve epigenetic regulation.

How well does the clustering of co-expressed genes reflect coregulation? Since a microarray snapshot identifying the groups of co-expressed genes does not account for the dynamically responsive nature of regulatory elements, it may be useful to obtain lists of co-expressed genes satisfying multiple discriminating criteria. For example, do the genes (1) change together under various conditions (Luscombe et al., 2004); (2) share common biological pathways (Okuda et al., 2006); and/or (3) show consistent anatomical expression in more than one brain structure? One possible combination using existing data for finding inhibitory subtype specific regulatory elements, would be to combine Sugino et al.'s (2006) microarray dataset with a complete survey of the Allen Mouse Brain Atlas (Lein et al., 2007). Inhibitory neurons show distinct patterns of expression throughout the brain, including the cerebellum, cortex, hippocampus and reticular thalamus. Therefore, genes that share common patterns of expression in many regions, and are found by microarray data to be enriched in a specific cell-type, could provide a more stringent and larger basis for identifying common regulatory elements.

Composite regulatory element (CRE) promoters appear to present a viable option for creating cell-type specific promoters. Indeed, of all of the promoters tested, the AAV-E1.1-NRSE vector showed the most potential for inhibitory neuron subtype selectivity. In addition, the simplicity of this promoter suggests that relatively simple modifications might also yield significant improvements. For example, further reduction in glial expression might be achieved by adding additional NRSE sites. And since Bessis et al. (1997) has shown that the distance between NRSE and other factors can affect whether the NRSF/NRSE restricts or enhances activity, the suppression activity of the NRSE sites might be enhanced by increasing the distance between the NRSE sites and the other

\section{REFERENCES}

Aparicio, S., Chapman, J., Stupka, E., Putnam, N., Chia, J. M., Dehal, P., Christoffels, A., Rash, S., Hoon, S., Smit, A., Gelpke, M. D., Roach, J., Oh, T., Ho, I. Y., Wong, M., Detter, C., Verhoef, F., Predki, P., Tay, A., Lucas, S., Richardson, P., Smith, S. F., Clark, M. S.,Edwards, Y. J., Doggett, N.,
Zharkikh, A., Tavtigian, S. V., Pruss, D., Barnstead, M., Evans, C., Baden, H., Powell, J., Glusman, G., Rowen, L., Hood, L., Tan, Y. H., Elgar, G., Hawkins, T., Venkatesh, B., Rokhsar, D., and Brenner, S. (2002). Whole-genome shotgun assembly and analysis of the genome of Fugu rubripes. Science 297, 1301-1310.

binding sites in the CRE. One option for increasing the activity of the AAV-DR1-NRSE vector might be to add multiple copies of the DR1 motif as is the case in the E1.1 vectors. Alternatively, since the Pal3 motif (Okuno et al., 2001) can bind the PPAR $\gamma$ homodimer without $\operatorname{RXR} \alpha$, this element may prove to drive stronger expression in PV+ cells. Despite the apparent simplicity of these vectors, the number and arrangement of factors in precise orders and at specific distances, consistent with the natural placements, might be important for correct regulation. Therefore the usefulness of regulatory elements as building blocks for obtaining specific and complex regulation may require extensive characterization of these elements. Given the selectivity of the AAV-E1.1-NRSE vector, the extremely short promoter sequences, and that expression datasets such as the microarray dataset by Sugino et al. (2006) can identify candidate transcription factors, the CRE approach may be a ripe strategy in the pursuit of cell-type specific promoters.

Neither of our promoter approaches achieved inhibitory neuron cell-type specificity. It is possible that there are few workable solutions for inhibitory neuron cell-type promoters given promoter complexities and the size limitations in AAV and LV. At this point, the only dependable method for transcriptional targeting of specific cell populations using inserted DNA is with large BAC sequences, which are used for the creation of transgenic animals (Heintz, 2001). One possible viral vector based alternative to AAV or LV may be the use of HSV vectors, which can incorporate BACs of up to $150 \mathrm{~kb}$ (Saeki et al., 1998). Efforts to make HSV suitable for gene therapy applications are ongoing (Berges et al., 2007), and may prove the best suited vector when cell-type specific control is desired. Alternatively, viral pseudotyping via capsid modifications may be a useful approach for cell-type specific targeting (Choi et al., 2005). Where smaller regulatory elements are required, multi-faceted approaches, including multi-pronged bioinformatic comparisons of co-expressed genes and composite regulatory element promoters are perhaps the most promising avenues of pursuit, and may yield new insights towards achieving cell-type specific regulation.

\section{ACKNOWLEDGMENTS}

We thank Yuchio Yanagawa for his contribution of GAD67-GFP knock-in mice. This work was supported by the NIH Neuroplasticity of Aging Training Grant AG000216 (awarded to UCSD), Chapman Charitable Trust, Aginsky Research Scholarship, and NIH Grants DA011828 and MH063912 to EMC.

\section{SUPPLEMENTARY MATERIAL}

The Supplementary Material for this article can be found online at http://www.frontiersin.org/neuralcircuits/paper/10.3389/ neuro.04/019.2009/

Batten, T. F., Cambre, M. L., Moons, L., and Vandesande, F. (1990). Comparative distribution of neuropeptideimmunoreactive systems in the brain of the green molly, Poecilia latipinna. J. Comp. Neurol. 302, 893-919.

Becerra,M.,Manso,M.J.,Rodriguez-Moldes, I., and Anadon, R. (1995). Ontogeny of somatostatin-immunoreactive systems in the brain of the brown trout(Teleostei) Anat. Embryol. 191, 119-137.

Berges, B. K., Wolfe, J.H., and Fraser, N. W. (2007). Transduction of brain by herpes simplex virus vectors. Mol. Ther. 15, 20-29.

Bessis, A., Champtiaux, N., Chatelin, L., and Changeux, J. P. (1997). The neuron-restrictive silencer element: 
a dual enhancer/silencer crucial for patterned expression of a nicotinic receptor gene in the brain. Proc. Natl. Acad. Sci. U.S.A. 94, 5906-5911.

Blasco-Ibanez, J. M., and Freund, T. F. (1997). Distribution, ultrastructure, and connectivity of calretininimmunoreactive mossy cells of the mouse dentate gyrus. Hippocampus 7, 307-320.

Brass, A. L., Kehrli, E., Eisenbeis, C. F., Storb, U., and Singh, H. (1996). Pip, a lymphoid-restricted IRF, contains a regulatory domain that is important for autoinhibition and ternary complex formation with the Ets factor PU.1. Genes Dev. 10, 2335-2347.

Brinon, J. G., Alonso, J. R., GarciaOjeda, E., Arevalo, R., Porteros, A., Velasco, A., and Aijon, J. (1994). Parvalbumin immunoreactivity in the telencephalic hemispheres of the tench, Tinca tinca. Arch. Ital. Biol. 132, 1-12.

Butscher, W. G., Powers, C., Olive, M., Vinson, C., and Gardner, K. (1998). Coordinate transactivation of the interleukin-2 CD28 response element by c-Rel and ATF-1/CREB2. J. Biol. Chem. 273, 552-560.

Calkins, D. J., Sappington, R. M., and Hendry, S. H. (2005). Morphological identification of ganglion cells expressing the alpha subunit of type II calmodulin-dependent protein kinase in the macaque retina. J. Comp. Neurol. 481, 194-209.

Callaway, E. M. (2005). A molecular and genetic arsenal for systems neuroscience. Trends Neurosci. 28, 196-201.

Casolaro, V., Georas, S. N., Song, Z., Zubkoff, I. D., Abdulkadir, S. A., Thanos, D., and Ono, S. J. (1995). Inhibition of NF-AT-dependent transcription by NF-kappa B: implications for differential gene expression in $\mathrm{T}$ helper cell subsets. Proc. Natl. Acad. Sci. U.S.A. 92, 11623-11627.

Castro, A., Becerra, M., Manso, M. J., and Anadon, R. (1999). Development of immunoreactivity to neuropeptide $\mathrm{Y}$ in the brain of brown trout (Salmo trutta fario). J. Comp. Neurol. 414, 13-32.

Castro, A., Becerra, M., Manso, M. J., and Anadon, R. (2003). Distribution and development of calretinin-like immunoreactivity in the telencephalon of the brown trout, Salmo trutta fario. J. Comp. Neurol. 467, 254-269.

Cauli, B., Audinat, E., Lambolez, B., Angulo, M.C., Ropert, N., Tsuzuki, K., Hestrin, S., and Rossier, J. (1997). Molecular and physiological diversity of cortical nonpyramidal cells. J. Neurosci. 17, 3894-3906.
Choi, V. W., McCarty, D. M., and Samulski, R. J. (2005). AAV hybrid serotypes: improved vectors for gene delivery. Curr. Gene Ther. 5, 299-310.

Cora, D., Herrmann, C., Dieterich, C., Di Cunto, F., Provero, P., and Caselle, M. (2005). Ab initio identification of putative human transcription factor binding sites by comparative genomics. BMC Bioinformatics 6, 110.

Defelipe, J., Gonzalez-Albo, M. C., Del Rio, M. R., and Elston, G. N. (1999). Distribution and patterns of connectivity of interneurons containing calbindin, calretinin, and parvalbumin in visual areas of the occipital and temporal lobes of the macaque monkey. J. Comp. Neurol. 412, 515-526.

Diamond, M. I., Miner, J. N., Yoshinaga, S. K., and Yamamoto, K. R. (1990). Transcription factor interactions: selectors of positive or negative regulation from a single DNA element. Science 249, 1266-1272.

Diaz-Regueira, S., and Anadon, R. (2000). Calretinin expression in specific neuronal systems in the brain of an advanced teleost, the grey mullet (Chelon labrosus). J. Comp. Neurol. 426, 81-105.

Dittgen, T., Nimmerjahn, A., Komai, S., Licznerski, P., Waters, J., Margrie, T. W., Helmchen, F., Denk, W., Brecht, M., and Osten, P. (2004). Lentivirusbased genetic manipulations of cortical neurons and their optical and electrophysiological monitoring in vivo. Proc. Natl. Acad. Sci. U.S.A. 101, 18206-18211.

Dong, J. Y., Fan, P. D., and Frizzell, R. A. (1996). Quantitative analysis of the packaging capacity of recombinant adeno-associated virus. Hum. Gene Ther. 7, 2101-2112.

Duan, D., Sharma, P., Yang, J., Yue, Y., Dudus, L., Zhang, Y., Fisher, K. J., and Engelhardt, J.F. (1998). Circular intermediates of recombinant adeno-associated virus have defined structural characteristics responsible for longterm episomal persistence in muscle tissue. J. Virol. 72, 8568-8577.

Ebersberger, I., Metzler, D., Schwarz, C., and Paabo, S. (2002). Genomewide comparison of DNA sequences between humans and chimpanzees. Am. J. Hum. Genet. 70, 1490-1497.

Freund, T. F., and Gulyas, A. I. (1991). GABAergic interneurons containing calbindin D28K or somatostatin are major targets of GABAergic basal forebrain afferents in the rat neocortex. J. Comp. Neurol. 314, 187-199.

Galimi, F., and Verma, I. M. (2002). Opportunities for the use of lentiviral vectors in human gene therapy. Curr. Top. Microbiol. Immunol. 261, 245-254.
Gibson, J. R., Beierlein, M., and Connors, B. W. (1999). Two networks of electrically coupled inhibitory neurons in neocortex. Nature 402, 75-79.

Gilligan, P., Brenner, S., and Venkatesh, B. (2003). Neurone-specific expression and regulation of the pufferfish isotocin and vasotocin genes in transgenic mice. J. Neuroendocrinol. 15 1027-1036.

Gonchar, Y., and Burkhalter, A. (1997). Three distinct families of GABAergic neurons in rat visual cortex. Cereb. Cortex 7, 347-358.

Gonchar, Y., and Burkhalter, A. (1999). Connectivity of GABAergic calretininimmunoreactive neurons in rat primary visual cortex. Cereb. Cortex 9 , 683-696.

Gupta, A., Wang, Y., and Markram, H. (2000). Organizing principles for a diversity of GABAergic interneurons and synapses in the neocortex. Science 287, 273-278

Heintz, N. (2001). BAC to the future: the use of bac transgenic mice for neuroscience research. Nat. Rev. Neurosci. 2, 861-870.

Hornung, J. P., and Celio, M. R. (1992). The selective innervation by serotoninergic axons of calbindin-containing interneurons in the neocortex and hippocampus of the marmoset. J. Comp. Neurol. 320, 457-467.

Huang, Y., Myers, S. J., and Dingledine, R. (1999). Transcriptional repression by REST: recruitment of Sin3A and histone deacetylase to neuronal genes. Nat. Neurosci. 2, 867-872.

Jones, E. G., Huntley, G. W., and Benson, D. L. (1994). Alpha calcium/ calmodulin-dependent protein kinase II selectively expressed in a subpopulation of excitatory neurons in monkey sensory-motor cortex: comparison with GAD-67 expression. J. Neurosci. 14, 611-629.

Karolchik, D., Kuhn, R. M., Baertsch, R., Barber, G. P., Clawson, H., Diekhans, M., Giardine, B., Harte, R.A., Hinrichs, A. S., Hsu, F., Kober, K. M., Miller, W., Pedersen, J. S., Pohl, A., Raney, B. J., Rhead, B., Rosenbloom, K.R.,Smith, K. E., Stanke, M., Thakkapallayil, A., Trumbower, H., Wang, T., Zweig, A. S., Haussler, D., and Kent, W. J. (2008). The UCSCGenome Browser Database: 2008 update. Nucleic Acids Res. 36, D773-D779.

Karube, F., Kubota, Y., and Kawaguchi, Y. (2004). Axon branching and synaptic bouton phenotypes in GABAergic nonpyramidal cell subtypes. J. Neurosci. 24, 2853-2865.

Kaspar, B. K., Vissel, B., Bengoechea, T., Crone,S., Randolph-Moore, L.,Muller, R., Brandon, E. P., Schaffer, D., Verma, I. M., Lee, K. F., Heinemann, S. F., and
Gage, F. H. (2002). Adeno-associated virus effectively mediates conditional gene modification in the brain. Proc. Natl. Acad. Sci. U.S.A. 99, 2320-2325.

Kawaguchi, Y. (1993). Groupings of nonpyramidal and pyramidal cells with specific physiological and morphological characteristics in rat frontal cortex. J. Neurophysiol. 69, 416-431.

Kawaguchi, Y., and Kubota, Y. (1996). Physiological and morphological identification of somatostatin- or vasoactive intestinal polypeptide-containing cells among GABAergic cell subtypes in rat frontal cortex. J. Neurosci. 16, 2701-2715.

Kawaguchi, Y., and Kubota, Y. (1997). GABAergic cell subtypes and their synaptic connections in rat frontal cortex. Cereb. Cortex 7, 476-486.

Kel, A. E., Gossling, E., Reuter, I., Cheremushkin, E., Kel-Margoulis, O. V., and Wingender, E. (2003). MATCH: a tool for searching transcription factor binding sites in DNA sequences. Nucleic Acids Res. 31, 3576-3579.

Kel, O. V., Romaschenko, A. G., Kel, A. E., Wingender, E., and Kolchanov, N. A. (1995). A compilation of composite regulatory elements affecting gene transcription in vertebrates. Nucleic Acids Res. 23, 4097-4103.

Kel-Margoulis, O. V., Kel, A. E., Reuter, I., Deineko, I. V., and Wingender, E. (2002). TRANSCompel: a database on composite regulatory elements in eukaryotic genes. Nucleic Acids Res. 30, 332-334.

Kent, W. J., Sugnet, C. W., Furey, T. S., Roskin, K. M., Pringle, T. H., Zahler, A. M., and Haussler, D. (2002). The human genome browser at UCSC. Genome Res. 12, 996-1006.

Kielbase, S. M., Bluthgen, N., Sers, C., Schafer, R., and Herzel, H. (2004). Prediction of cis-regulatory elements of coregulated genes. Genome Inform. $15,117-124$.

King, M. C., and Wilson, A. C. (1975) Evolution at two levels in humans and chimpanzees. Science 188, 107-116.

Klein-Hessling, S., Schneider, G., Heinfling, A., Chuvpilo, S., and Serfling, E. (1996). HMG I(Y) interferes with the DNA binding of NF-AT factors and the induction of the interleukin 4 promoter in T cells. Proc. Natl. Acad. Sci. U.S.A. 93, 15311-15316.

Kugler, S., Kilic, E., and Bahr, M. (2003). Human synapsin 1 gene promoter confers highly neuron-specific longterm transgene expression from an adenoviral vector in the adult rat brain depending on the transduced area. Gene Ther. 10, 337-347. 
Kumar, M., Keller, B., Makalou, N., and Sutton, R. E. (2001). Systematic determination of the packaging limit of lentiviral vectors. Hum. Gene Ther. 12, 1893-1905.

Lein, E. S., Hawrylycz, M. J., Ao, N., Ayres, M., Bensinger, A., Bernard, A., Boe, A. F., Boguski, M. S., Brockway, K. S., Byrnes, E. J., Chen, L., Chen, T. M., Chin, M. C., Chong, J., Crook, B. E., Czaplinska, A., Dang, C. N., Datta, S., Dee, N. R., Desaki, A. L., Desta, T., Diep, E., Dolbeare, T. A., Donelan, M. J., Dong, H. W., Dougherty, J. G., Duncan, B. J., Ebbert, A. J., Eichele, G., Estin, L. K., Faber, C., Facer, B. A., Fields, R., Fischer, S. R., Fliss, T. P., Frensley, C., Gates, S. N., Glattfelder, K. J., Halverson, K. R., Hart, M. R., Hohmann, J. G., Howell, M. P., Jeung, D. P., Johnson, R. A., Karr, P. T., Kawal, R., Kidney, J. M., Knapik, R. H., Kuan, C. L., Lake, J. H., Laramee, A. R., Larsen, K. D., Lau, C., Lemon, T. A., Liang, A. J., Liu, Y., Luong, L. T., Michaels, J., Morgan, J. J., Morgan, R. J., Mortrud, M. T., Mosqueda, N. F., Ng, L. L., Ng, R., Orta, G. J., Overly, C. C., Pak, T. H., Parry, S. E., Pathak, S. D., Pearson, O. C., Puchalski, R. B., Riley, Z. L., Rockett, H. R., Rowland, S. A., Royall, J. J., Ruiz, M. J., Sarno, N. R., Schaffnit, K., Shapovalova, N. V., Sivisay, T., Slaughterbeck, C. R., Smith, S. C., Smith, K. A., Smith, B. I., Sodt, A. J., Stewart, N. N., Stumpf, K. R., Sunkin, S. M., Sutram, M., Tam, A., Teemer, C. D., Thaller, C., Thompson, C. L., Varnam, L. R., Visel, A., Whitlock, R. M., Wohnoutka, P. E., Wolkey, C. K., Wong, V. Y., Wood, M., Yaylaoglu, M. B., Young, R. C., Youngstrom, B. L., Yuan, X. F., Zhang, B., Zwingman, T. A., and Jones, A. R. (2007). Genome-wide atlas of gene expression in the adult mouse brain. Nature 445, 168-176.

Linhoff, M.W., Wright, K. L., and Ting, J. P. (1997). CCAAT-binding factor NF-Y and RFX are required for in vivo assembly of a nucleoprotein complex that spans 250 base pairs: the invariant chain promoter as a model. Mol. Cell. Biol. 17, 4589-4596.

Liu, X. B., and Jones, E. G. (1996). Localization of alpha type II calcium calmodulin-dependent protein kinase at glutamatergic but not gammaaminobutyric acid (GABAergic) synapses in thalamus and cerebral cortex. Proc. Natl. Acad. Sci. U.S.A. 93, 7332-7336.

Lunyak,V.V.,Burgess, R.,Prefontaine, G. G., Nelson, C., Sze, S. H., Chenoweth, J., Schwartz, P., Pevzner, P. A., Glass, C., Mandel, G., and Rosenfeld, M. G. (2002). Corepressor-dependent silencing of chromosomal regions encoding neuronal genes. Science 298, 1747-1752.

Luo, L., Callaway, E. M., and Svoboda, K. (2008). Genetic dissection of neural circuits. Neuron 57, 634-660.

Luscombe, N. M., Babu, M. M., Yu, H., Snyder, M., Teichmann, S. A., and Gerstein, M. (2004). Genomic analysis of regulatory network dynamics reveals large topological changes. Nature 431, 308-312.

Marr, R. A., Guan, H., Rockenstein, E., Kindy, M., Gage, F. H., Verma, I., Masliah, E., and Hersh, L. B. (2004). Neprilysin regulates amyloid Beta peptide levels. J. Mol. Neurosci. 22, 5-11.

Matys, V., Fricke, E., Geffers, R., Gossling, E., Haubrock, M., Hehl, R., Hornischer, K., Karas, D., Kel, A. E., Kel-Margoulis, O. V., Kloos, D. U., Land, S., Lewicki-Potapov, B., Michael, H., Munch, R., Reuter, I., Rotert, S., Saxel, H., Scheer, M., Thiele, S., and Wingender, E. (2003). TRANSFAC: transcriptional regulation, from patterns to profiles. Nucleic Acids Res. 31, 374-378.

Melendez-Ferro,M.,Perez-Costas, E., VillarCheda, B., Abalo, X. M., RodriguezMunoz, R., Rodicio, M.C., and Anadon, R. (2002). Ontogeny of gammaaminobutyric acid-immunoreactive neuronal populations in the forebrain and midbrain of the sea lamprey. J. Comp. Neurol. 446, 360-376.

Meskenaite, V. (1997). Calretinin-immunoreactive local circuit neurons in area 17 of the cynomolgus monkey, Macaca fascicularis. J. Comp. Neurol. 379, 113-132.

Millecamps, S., Kiefer, H., Navarro, V., Geoffroy, M. C., Robert, J. J., Finiels, F., Mallet, J., and Barkats, M. (1999). Neuron-restrictive silencer elements mediate neuron specificity of adenoviral gene expression. Nat. Biotechnol. 17, 865-869.

Monahan, P.E., and Samulski, R. J. (2000). Adeno-associated virus vectors for gene therapy: more pros than cons? Mol. Med. Today 6, 433-440.

Moreno, C. S., Emery, P., West, J. E., Durand, B., Reith, W., Mach, B., and Boss, J. M. (1995). Purified X2 binding protein $(\mathrm{X} 2 \mathrm{BP})$ cooperatively binds the class II MHC X box region in the presence of purified RFX, the X box factor deficient in the bare lymphocyte syndrome. J. Immunol. 155, 4313-4321.

Morgenstern, B. (1999). DIALIGN 2: improvement of the segmentto-segment approach to multiple sequence alignment. Bioinformatics 15, 211-218.

Muhlethaler-Mottet, A., Di Berardino, W., Otten, L. A., and Mach, B. (1998). Activation of the MHC class II transactivator CIITA by interferongamma requires cooperative interaction between Statl and USF-1. Immunity 8, 157-166.

Naldini, L., Blomer, U., Gage, F. H., Trono, D., and Verma, I. M. (1996a). Efficient transfer, integration, and sustained long-term expression of the transgene in adult rat brains injected with a lentiviral vector. Proc. Natl. Acad. Sci. U.S.A. 93, 11382-11388.

Naldini, L., Blomer, U., Gallay, P., Ory, D., Mulligan, R., Gage, F. H., Verma, I. M., and Trono, D. (1996b). In vivo gene delivery and stable transduction of nondividing cells by a lentiviral vector. Science 272, 263-267.

Naruse, Y., Aoki, T., Kojima, T., and Mori, N. (1999). Neural restrictive silencer factor recruits $\mathrm{mSin} 3$ and histone deacetylase complex to repress neuron-specific target genes. Proc. Natl. Acad. Sci. U.S.A. 96, 13691-13696.

Nathanson, J. L., Yanagawa, Y., Obata, K. and Callaway, E.M.(2009).Preferential labeling of inhibitory and excitatory cortical neurons by endogenous tropism of adeno-associated virus and lentivirus vectors. Neuroscience 161, 441-450.

Okuda, S., Katayama, T., Kawashima, S., Goto, S., and Kanehisa, M. (2006). ODB: a database of operons accumulating known operons across multiple genomes. Nucleic Acids Res. 34, D358-362.

Okuno, M., Arimoto, E., Ikenobu, Y., Nishihara, T., and Imagawa, M. (2001). Dual DNA-binding specificity of peroxisome-proliferator-activated receptor gamma controlled by heterodimer formation with retinoid $\mathrm{X}$ receptor alpha. Biochem. J. 353, 193-198.

Parra, P., Gulyas, A. I., and Miles, R. (1998). How many subtypes of inhibitory cells in the hippocampus? Neuron 20, 983-993.

Patton, P.E., and McNaughton, B. (1995) Connection matrix of the hippocampal formation: I. The dentate gyrus. Hippocampus 5, 245-286.

Peters, A., and Regidor, J. (1981). A reassessment of the forms of nonpyramidal neurons in area 17 of cat visual cortex. J. Comp. Neurol. 203, 685-716.

Preuss, T. M., and Kaas, J. H. (1996). Parvalbumin-like immunoreactivity of layer $\mathrm{V}$ pyramidal cells in the motor and somatosensory cortex of adult primates. Brain Res. 712, 353-357.

Rabinowitz, J. E., Rolling, F., Li, C., Conrath, H., Xiao, W., Xiao, X., and Samulski, R. J. (2002). Cross-packaging of a single adeno-associated virus (AAV) type 2 vector genome into multiple AAV serotypes enables transduction with broad specificity. J. Virol.76, 791-801.
Rodriguez-Trelles, F., Tarrio, R., and Ayala, F. J. (2003). Evolution of cis-regulatory regions versus codifying regions. Int. J. Dev. Biol. 47, 665-673.

Saeki, Y., Ichikawa, T., Saeki, A., Chiocca, E.A., Tobler, K., Ackermann, M., Breakefield, X. O., and Fraefel, C. (1998). Herpes simplex virus type 1 DNA amplified as bacterial artificial chromosome in Escherichia coli: rescue of replication-competent virus progeny and packaging of amplicon vectors. Hum. Gene Ther. 9, 2787-2794.

Scardigli, R., Baumer, N., Gruss, P., Guillemot, F., and Le Roux, I. (2003). Direct and concentration-dependent regulation of the proneural gene Neurogenin 2 by Pax6. Development 130, 3269-3281.

Somogyi, P. (1977). A specific 'axo-axonal' interneuron in the visual cortex of the rat. Brain Res. 136, 345-350.

Stuhmer, T., Puelles, L., Ekker, M., and Rubenstein, J. L. (2002). Expression from a Dlx gene enhancer marks adult mouse cortical GABAergic neurons. Cereb. Cortex 12, 75-85.

Sugino, K., Hempel, C. M., Miller, M. N., Hattox, A. M., Shapiro, P., Wu, C., Huang, Z. J., and Nelson, S. B. (2006). Molecular taxonomy of major neuronal classes in the adult mouse forebrain. Nat. Neurosci. 9, 99-107.

Takeuchi, A., Reddy, G. S., Kobayashi, T., Okano, T., Park, J., and Sharma, S. (1998). Nuclear factor of activated $\mathrm{T}$ cells (NFAT) as a molecular target for lalpha,25-dihydroxyvitamin D3-mediated effects. J. Immunol. 160 , 209-218.

Tamamaki, N., Yanagawa, Y., Tomioka, R., Miyazaki, J., Obata, K., and Kaneko, T. (2003). Green fluorescent protein expression and colocalization with calretinin, parvalbumin, and somatostatin in the GAD67-GFP knock-in mouse. J. Comp. Neurol. 467, 60-79.

Tamas, G., Somogyi, P., and Buhl, E. H. (1998). Differentially interconnected networks of GABAergic interneurons in the visual cortex of the cat. J. Neurosci. 18, 4255-4270.

Thomson, A. M., and Deuchars, J. (1997). Synaptic interactions in neocortical local circuits: dual intracellular recordings in vitro. Cereb. Cortex 7 , 510-522.

Tiscornia, G., Singer, O., and Verma, I. M. (2006). Production and purification of lentiviral vectors. Nat. Protoc. 1, 241-245.

Venkatesh, B., Si-Hoe, S. L., Murphy, D., and Brenner, S. (1997). Transgenic rats reveal functional conservation of regulatory controls between the Fugu isotocin and rat oxytocin genes. Proc. Natl. Acad. Sci. U.S.A. 94, 12462-12466. 
Woolfe, A., Goodson, M., Goode, D. K., Snell, P., McEwen, G. K., Vavouri, T., Smith, S. F., North, P., Callaway, H., Kelly, K., Walter, K., Abnizova, I., Gilks, W., Edwards, Y. J., Cooke, J. E., and Elgar, G. (2005). Highly conserved non-coding sequences are associated with vertebrate development. PLoS Biol. 3, e7. doi: 10.1371/journal. pbio.0030007.

Xu, X., Roby, K. D., and Callaway, E. M. (2006). Mouse cortical inhibitory neuron type that coexpresses somatostatin and calretinin. J. Comp. Neurol. 499, 144-160.

Yang, J., Zhou, W., Zhang, Y., Zidon, T., Ritchie, T., and Engelhardt, J.F. (1999).
Concatamerization of adeno-associated virus circular genomes occurs through intermolecular recombination. J. Virol. 73, 9468-9477.

Zhang, T., Tan, Y. H., Fu, J., Lui, D., Ning, Y., Jirik, F. R., Brenner, S., and Venkatesh, B. (2003). The regulation of retina specific expression of rhodopsin gene in vertebrates. Gene 313, 189-200.

Zhang, Z., and Gerstein, M. (2003). Of mice and men: phylogenetic footprinting aids the discovery of regulatory elements. J. Biol. 2, 11.

Zolotukhin, S., Byrne, B. J., Mason, E., Zolotukhin, I., Potter, M., Chesnut, K., Summerford, C., Samulski, R. J., and
Muzyczka, N. (1999). Recombinant adeno-associated virus purification using novel methods improves infectious titer and yield. Gene Ther. 6, 973-985.

Conflict of Interest Statement: The authors declare that research was conducted in the absence of any commercial or financial relationships that could be construed as a potential conflict of interest.

Received: 15 June 2009; paper pending published: 10 September 2009; accepted: 13 October 2009; published online: 09 November 2009.
Citation: Nathanson JL, Jappelli R, Scheeff ED, Manning G, Obata K, Brenner $S$ and Callaway EM (2009) Short promoters in viral vectors drive selective expression in mammalian inhibitory neurons, but do not restrict activity to specific inhibitory cell-types. Front. Neural Circuits 3:19. doi: 10.3389/neuro.04.019.2009

Copyright (C) 2009 Nathanson, Jappelli, Scheeff, Manning, Obata, Brenner and Callaway. This is an open-access article subject to an exclusive license agreement between the authors and the Frontiers Research Foundation, which permits unrestricted use, distribution, and reproduction in any medium, provided the original authors and source are credited. 